\title{
Price Cap Models in Pharmaceutical Online-to-Offline Supply Chains
}

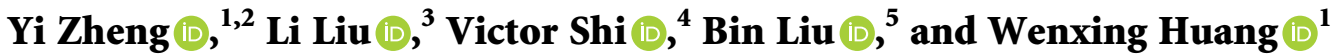 \\ ${ }^{1}$ Department of Industrial Engineering, School of Management, Xihua University, Chengdu 610039, China \\ ${ }^{2}$ China Tourism Academy, Beijing 100005, China \\ ${ }^{3}$ Research Institute of International Economics and Management Science, Xihua University, Chengdu 610039, China \\ ${ }^{4}$ Lazaridis School of Business and Economics, Wilfrid Laurier University, ON N2L 3C5, Waterloo, Canada \\ ${ }^{5}$ Shanghai Business School, Shanghai, China \\ Correspondence should be addressed to Bin Liu; liubin@sbs.edu.cn
}

Received 26 June 2020; Revised 25 August 2020; Accepted 15 September 2020; Published 6 November 2020

Academic Editor: Peter Bian

Copyright (c) 2020 Yi Zheng et al. This is an open access article distributed under the Creative Commons Attribution License, which permits unrestricted use, distribution, and reproduction in any medium, provided the original work is properly cited.

\begin{abstract}
Pharmaceutical supply chains are often highly complex with conflicting objectives of social welfare and profit maximization. Furthermore, there are various stakeholders including pharmaceutical manufacturer, distributors, retailers, patients, and the government. In this paper, we consider a two-stage supply chain consisting of one pharmaceutical manufacturer and a pharmacy with online and offline channels. We focus on four price cap models: no price cap regulation, pharmaceutical manufacturer's price cap regulation, pharmacy price cap regulation, and linkage price cap regulation. We apply game theory, investigate how the price cap regulations affect the firms' pricing, and evaluate the economic performance and social welfare of the dual-channel pharmaceutical supply chain. Our findings show that first, like the single-channel pharmaceutical supply chain, the profit of the regulated firm always decreases and the profit of the unregulated firm always increases when they are under one-sided price cap regulations. Second, the impacts of the linkage price cap regulation on the supply chain are more complicated depending on the linkage coefficient and market share. Overall, our findings can provide theoretical and practical insights to help the government devise price cap regulations for complex modern pharmaceutical supply chains.
\end{abstract}

\section{Introduction}

Human health not only affects individual employment and survival but also largely determines a country's economic growth and prosperity by the United Nations [1]. In turn, human health depends on the improvement of a country's medical and health system. In 2010, global medical and health expenditures amounted to US \$6.5 trillion, accounting for $10.49 \%$ of the world's GDP. The United States spent the world's highest on medical and health expenditures, reaching US $\$ 257.5$ billion in 2012, accounting for $17.61 \%$ of its GDP [2]. The pharmaceutical industry is a basic component of the medical and health economy. Among all medical and health products, drug expenditure accounts for $20-30 \%$ of global medical and health expenditure [3], which is one of the most important expenditures on medical and health [4]. The growth in pharmaceutical spending is attributed to two main reasons: increased pharmaceutical use and the introduction of new higher-priced products. In terms of growth rate, the global pharmaceutical industry grew at a rate of about $3-5 \%$ in 2009 ; it is expected to continue to grow at a rate of $4-6 \%$ in the next few years [5].

As a special commodity for curing diseases and saving lives, the quality and safety of medicines are particularly important [6], and the pressure to compress the cost is also very urgent [7]. The high cost of medicines mainly comes from the circulation link [8], which is as high as $40-50 \%$ in China [9]. However, medical institutions often take advantage of their monopoly position in the pharmaceutical supply chain to chase high drug profits, deviating from the nature of public welfare, and "expensive medical treatment" has become one of the most prominent social problems in 
many countries like China [10]. In order to prevent the pharmaceutical supply chain led by medical institutions from chasing high drug profits, the government has adopted price cap regulations. In 2018, "the $(4+7)$ Urban Drug Centralized Procurement Documents" was released, and pilot trials of the "volume procurement" policy of public hospitals were started in 11 cities with Shanghai as the representative city, realizing cross-regional joint centralized procurement. This policy has achieved good results and achieved a substantial drop in drug prices. How to ensure the quality of medicines while reducing the price of medicines has become a problem that government departments and patients attach great importance to. In addition, the government's price limit control for drugs has been constantly reformed in the face of controversy, and various drug price control measures have been implemented, such as comprehensive drug price control, drug retail price control, and price increase rate control [11].

Under the maximum price policy for medicines, a longterm game within the medicine supply chain has gradually formed a balance between profitability and public welfare. Due to the particularity of drugs, traditional distribution channels of drugs are divided into public hospitals and social pharmacies. Therefore, under the government's control of public hospital bidding and procurement and the control of drug prices in social pharmacies, it is particularly important to consider how drug retailers choose channel sales, how to accurately target consumers, and how to ensure their own profits.

With the introduction of the online drug sales policy, drug suppliers such as "Jointown" and "yunnan baiyao" have set up online sales channels and implemented the dualchannel drug sales strategy, thus breaking the traditional balance of interests in the pharmaceutical supply chain. By 2020, more than 1,000 drug suppliers in China have opened online channels. In the context of the dual-channel pharmaceutical supply chain, it has become the focus of social concern whether the price-fixing policy can continue to control drug prices and whether the public welfare of medical institutions can ensure social welfare. In addition, the development of online drug sales channels has broken the monopoly of medical institutions on the drug market, and the dominant position of medical institutions in the pharmaceutical supply chain has been balanced and surpassed by some large drug suppliers. Consequently, drug retailers have become the dominant players in pharmaceutical supply chains [12]. Therefore, it is of great theoretical and practical significance to study drug retailers and their dual-channel supply chains in the context of price cap regulations.

Our research aims to fulfill this gap through addressing the following key questions: what is the best strategy for a pharmaceutical supply chain under price cap regulations? What are the impacts of the price caps on pricing decisions, profits, and social welfare? How does market competition affect a pharmaceutical online-to-offline (O2O) supply chain?

In order to answer these questions, this research focuses on pharmaceutical supply chains under three price cap models. We consider a supply chain with one pharmaceutical manufacturer and one pharmacy with an $\mathrm{O} 2 \mathrm{O}$ mixed channel. The pharmacy is the Stackelberg leader, and the pharmaceutical manufacturer is the follower. The pharmacy retailer holds both physical virtual online shops and retail stores. We compare the optimal prices for both online and offline channels, profits, and social welfare under the models without and with price cap regulation.

In this paper, we make the following major contributions. First, our research complements the existing literature by focusing on the pricing strategies from the pharmacy's point of view in an $\mathrm{O} 2 \mathrm{O}$ mixed dual channel. Second, we not only derive the optimal pricing strategies for the pharmaceutical $\mathrm{O} 2 \mathrm{O}$ supply chain that operates both online and offline channels to consumers, but also investigate the impacts of three price cap regulations. Third, the three main results provide interesting insights on the appropriate pricing strategies which can support pharmacies who operate or intend to operate an $\mathrm{O} 2 \mathrm{O}$ mixed dual channels.

After a review of the literature in Section 2, the model and assumptions are provided in Section 3. In Section 4, the effects of price cap regulation on the pricing, profit, and social welfare are discussed. Section 5 discusses the impact of the linkage coefficient and offline market share on the pharmaceutical supply chain. Finally, we present managerial insights and discuss directions for future work in Section 6.

\section{Literature Review}

Nowadays, consumers can shop on multiple retailing channels, such as brick-and-mortar stores, online stores, mobile stores, and even social network platforms. Much of the literature relates to the problem of operational decision for pharmaceutical supply chains. Here, we review the studies highly related to our research, which can be classified into two categories: the first is on operations management in $\mathrm{O} 2 \mathrm{O}$ supply chain and the second is on operational decisions of the pharmaceutical supply chain.

2.1. Online to Offline. With the rapid development of e-commerce, many retailers such as Wal-Mart, Alibaba, and Noble have opened online channels. As a result, dualchannel supply chains and the term $\mathrm{O} 2 \mathrm{O}$ have received more and more research attention [13-15]. Tsay and Agrawal [16] find that adding a direct channel is beneficial to the retailer and the manufacturer under certain conditions. Cattani et al. [17] analyzed the potential conflicts between the traditional channel and the direct channel and proposed an equalpricing strategy to maximize the profit of the manufacturer for O2O channels. Huang and Swaminathan [18] investigated the optimal pricing strategies for the products which are sold via an online channel and a traditional channel. In addition, they also explored the pricing and profit under different degrees of channel competition. Yan and Pei [19] showed that cooperative advertisement can effectively alleviate the channel conflict. Chen et al. [20] derived the optimal prices and profits of a manufacturer and a retailer under different power structures (including Manufacturer-Stackelberg, 
Retailer-Stackelberg, and Nash) in a retail service supply chain with an $\mathrm{O} 2 \mathrm{O}$ mixed dual channel. Xiao and Shi [21] explored the pricing and channel priority strategies of a dual-channel supply chain composed by an online channel and a brick-and-mortar and examined the impacts of channel coordination and time sequence. Although all the aforementioned papers discuss pricing strategies, competition, and cooperation of a dual-channel supply chain in the context of $\mathrm{O} 2 \mathrm{O}$, they omit the impacts of price cap regulations on dual-channel supply chains.

2.2. Pharmaceutical Supply Chain. In recent years, research related to pharmaceutical supply chains has received increasing attention from scholars [7, 22, 23]. Related papers are reviewed and summarized below.

2.2.1. Distribution Network Design. Sousa et al. [24] studied the dynamic programming problem of the global supply chain configuration of pharmaceutical companies with the goal of profit-maximizing. They developed an effective algorithm to solve it considering production and distribution costs and tax rates in different locations. A. Nagurney and L. S. Nagurney [25] built an easy-to-handle network model and computation method for a medical supply chain. Nagurney et al. [26] studied a pharmaceutical supply chain equilibrium and dynamic network model considering outsourcing, price, and quality competition to find the optimal pharmaceutical logistics that minimizes the total cost. Based on the reality of drug distribution in Europe and the United States, the existing research has studied the design of drug distribution network from the perspective of pharmaceutical companies but not from the perspective of collection and distribution of drug distributors. On the other hand, the unique purpose of drugs to cure patients determines that the design of the drug distribution network should not only pursue low cost but also consider the constraints of service level. de Magalhães and de Sousa [8] used a dynamically designed variable path system to study the optimal distribution path of drugs from the perspective of drug distributors. Liang [27] studied the distribution center planning of pharmaceutical distribution companies in the context of centralized procurement and distribution. The studies above do focus on the design of the drug distribution network from the perspective of drug distributors but do not consider the constraints and impact of service levels. Shang et al. [28] took customer satisfaction rate as the service level constraint and employed noninteger linear programming to design a drug distribution network with the goal of minimizing distribution cost. However, they only consider the demand satisfaction rate and delivery timeliness rate.

2.2.2. Procurement and Distribution Management. Talluri et al. [29] studied the safety inventory management of multinational pharmaceutical companies based on inventory, considering both the variability of demand and supply. Danas et al. [30] applied the Ned-MASTA taxonomy to the inventory management of hospital pharmacies to improve the efficiency of operation management. Boulaksil and Fransoo [31] analyzed the impact of outsourcing on the drug ordering process. Shen et al. [32] proposed an improved pharmaceutical economic production model to minimize the cost of guaranteed inventory in consideration of the minimum inventory constraint. Pazirandeh [33] summarized the strategic procurement and established a decisionmaking framework for the procurement and distribution of vaccines in developing countries. Zhao et al. [34] studied the multicycle stochastic inventory problem of manufacturers and distributors under the service charge and investment purchase model, derived their optimal strategy, and developed a program to calculate policy parameters. Their research shows that service contract can improve the profit of the whole supply chain. The above studies considered the situation of a single product. Ying and Breen [35] constructed an integrated green drug supply chain model that includes all key stakeholders to improve the environmental, economic, and safety performance of drug management and distribution. Niziolek et al. [36] studied the direct distribution strategy of drugs and discussed the impact of different distribution frequencies and volumes on transportation and inventory costs through simulation. They believed that the mixed distribution strategy significantly reduced the total cost of the drug supply chain. The abovementioned literature separately researches the procurement and distribution of pharmaceutical logistics management.

\section{Models and Equilibrium Analysis}

3.1. Model Description and Assumptions. We consider a twoechelon dual-channel pharmaceutical supply chain consisting of a pharmaceutical manufacturer and a pharmacy with online and offline channels. Pharmacies often play a leading role in supply chains as the main buyers of pharmaceutical manufacturers. Therefore, we assume the pharmacy as the Stackelberg leader and the pharmaceutical manufacturer as the Stackelberg follower. The pharmacy buys drugs from the pharmaceutical manufacturer at wholesale price $w$ and then sells to the patient through the offline channel for the offline retail price $p_{1}$ or sells to the patient through the online channel for the online retail price $p_{2}$. For the pharmaceutical manufacturer, his production cost is denoted as $c$. In addition, regarding the channel setup cost of the pharmacy, the setup cost of the offline channel is denoted as $c_{1}$, and the setup cost of the online channel is denoted as $c_{2}$. It usually requires more investment and capital to build the online channel, so we assume $c_{2}>c_{1}$. Furthermore, in this paper, for clarity, we assume that the offline retailer's price is higher than the online retail price. That is, $p_{1}>p_{2}$. Next, we define parameters and variables as summarized in Table 1. Finally, we assume that the pharmaceutical manufacturer and the pharmacy are rational and selfinterested, each aiming for profit-maximizing.

Following Mukhopadhyay et al. [37], Shang et al. [38], and Chen et al. [39], we assume that the customer demand 
TABle 1: Notations.

\begin{tabular}{lc}
\hline Notations & Descriptions \\
\hline$c$ & Pharmaceutical manufacturer's unit production cost \\
$c_{1}$ & Offline channel's unit cost \\
$c_{2}$ & Online channel's unit cost \\
$w$ & Pharmaceutical manufacturer's unit wholesale cost \\
$p_{1}$ & Pharmacy's unit offline retail price; $p_{1}>w>c_{1}$ \\
$p_{2}$ & Pharmacy's unit online retail price; $p_{2}>w>c_{2}$ \\
$\bar{w}$ & Wholesale price cap imposed by the government \\
$\bar{p}$ & Retail price cap imposed by the government \\
$d_{1}$ & The customer demand via offline \\
$d_{2}$ & The customer demand via online \\
$\phi$ & Linkage coefficient between the wholesale price cap \\
& and the retail price cap under the linkage price cap \\
$\pi_{m}(w)$ & regulation, $0<\phi<1$ \\
$\pi_{r}\left(p_{1}, p_{2}\right)$ & Pharmaceutical manufacturer's profit \\
$\pi$ & Pharmacy's profit \\
$C$ & Total profit of the pharmaceutical supply chain, \\
$W$ & $\pi=\pi_{m}(w)+\pi_{r}\left(p_{1}, p_{2}\right)$ \\
\hline
\end{tabular}

via the offline channel is $d_{1}\left(p_{1}, p_{2}\right)=\theta \alpha-\beta p_{1}+\gamma p_{2}$, and the customer demand via the online channel is $d_{2}\left(p_{1}, p_{2}\right)=(1-\theta) \alpha-\beta p_{2}+\gamma p_{1}, \beta>\gamma$. In the demand functions, $\alpha$ means the base market, $\theta \alpha$ represents the offline market share, and $(1-\theta) \alpha$ represents the online market share. $\beta$ means the self-price sensitivity and $\gamma$ means the cross-price sensitivity. $\beta>\gamma$ means the self-price sensitivity is higher than the cross-price sensitivity. Based on the demand functions above, the pharmaceutical manufacturer's profit $\pi_{m}(w)$ is

$$
\begin{gathered}
\pi_{m}(w)=(w-c) d_{1}+(w-c) d_{2}, \\
\pi_{m}(w)=(w-c)\left[\theta \alpha-\beta p_{1}+\gamma p_{2}\right]+(w-c)\left[(1-\theta) \alpha-\beta p_{2}+\gamma p_{1}\right] .
\end{gathered}
$$

The first and second parts of (2) represent the pharmaceutical manufacturer's profit from the pharmacy's offline and online sales, respectively. The marginal profit of the offline channel is $m_{1}=p_{1}-w$ and the marginal profit of the online channel is $m_{2}=p_{2}-w$. The pharmaceutical manufacturer's profit $\pi_{m}(w)$ can be expressed as

$$
\pi_{m}(w)=(w-c)\left[\alpha-(\beta-\gamma)\left(m_{1}+m_{2}+2 w\right)\right] .
$$

The pharmacy's profit $\pi_{r}\left(p_{1}, p_{2}\right)$ is

$$
\begin{aligned}
\pi_{r}\left(p_{1}, p_{2}\right)= & \left(p_{1}-w-c_{1}\right) d_{1}+\left(p_{2}-w-c_{2}\right) d_{2}, \\
\pi_{r}\left(p_{1}, p_{2}\right)= & \left(p_{1}-w-c_{1}\right)\left[\theta \alpha-\beta p_{1}+\gamma p_{2}\right] \\
& +\left(p_{2}-w-c_{2}\right)\left[(1-\theta) \alpha-\beta p_{2}+\gamma p_{1}\right] .
\end{aligned}
$$

The first and second parts of this formula represent the pharmacy's profit from the offline and online sales, respectively. Social welfare consists of the patient surplus, the profit of the pharmaceutical manufacturer, and the profit of the pharmacy. Following Cowan et al. [40] and Jin et al. [41], the patient surplus $C$ can be written as

$$
\begin{gathered}
\int_{0}^{\theta \alpha-\beta p_{1}+\gamma p_{2}}\left(\frac{\theta \alpha-x+\gamma p_{2}}{\beta}-p_{1}\right) \mathrm{d} x+\int_{0}^{(1-\theta) \alpha-\beta p_{2}+\gamma p_{1}} \\
\cdot\left(\frac{(1-\theta) \alpha+\gamma p_{1}-y}{\beta}-p_{2}\right) \mathrm{d} y \\
=\frac{\left(\theta \alpha-\beta p_{1}+\gamma p_{2}\right)^{2}+\left[(1-\theta) \alpha-\beta p_{2}+\gamma p_{1}\right]^{2}}{2 \beta} .
\end{gathered}
$$

3.2. Price Cap Models. In this model, the pharmacy is the leader and the pharmaceutical manufacturer is the follower, which means that pharmacy plays a leadership role when they are making their decisions, the sequence of events is as follows. Firstly, the pharmaceutical manufacturer decides the wholesale price given the pharmacy's retail price. Then, the pharmacy decides his offline and online retail prices in response to the pharmaceutical manufacturer so as to maximize his profit. Finally, when the customer demand is realized, the pharmaceutical manufacturer and the pharmacy will gain their revenues. There are several potential situations in the pharmaceutical supply chain:

(i) RN model: in a RN model, the government has no price cap regulation on the pharmaceutical manufacturer and the pharmacy. The pharmaceutical manufacturer's profit-maximizing problem is

$$
\operatorname{Max}_{w^{r n}} \pi_{m}\left(w^{r n}\right)=\left(w^{r n}-c\right)\left[\alpha-(\beta-\gamma)\left(p_{1}^{r n}+p_{2}^{r n}\right)\right] .
$$

The pharmacy's profit-maximizing problem is

$\operatorname{Max}_{1}^{\max , p_{2}^{r n}} \pi_{r}\left(p_{1}^{r n}, p_{2}^{r n}\right)=\left(p_{1}^{r n}-w^{r n}-c_{1}\right) d_{1}^{r n}+\left(p_{2}^{r n}-w^{r n}-c_{2}\right) d_{2}^{r n}$.

(ii) RM model: in a RM model, the government regulates only the upstream pharmaceutical manufacturer by setting a wholesale price cap, $\bar{w}$. It means that the pharmaceutical manufacturer's wholesale price cannot exceed the wholesale price cap. The pharmaceutical manufacturer's profit-maximizing problem is

$$
\begin{aligned}
& \operatorname{Max}_{w^{r m}} \pi_{m}\left(w^{r m}\right)=\left(w^{r m}-c\right)\left[\alpha-(\beta-\gamma)\left(p_{1}^{r m}+p_{2}^{r m}\right)\right] \\
& \text { s.t. } \quad w^{r m} \leq \bar{w} .
\end{aligned}
$$

The pharmacy's profit-maximizing problem is

$$
\underset{p_{1}^{r m}, p_{2}^{r m}}{\operatorname{Max}} \pi_{r}\left(p_{1}^{r m}, p_{2}^{r m}\right)=\left(p_{1}^{r m}-w^{r m}-c_{1}\right) d_{1}^{r m}+\left(p_{2}^{r m}-w^{r m}-c_{2}\right) d_{2}^{r m} .
$$

(iii) RR model: in a RR model, the government regulates only the downstream pharmacy by setting a retail price cap, $\bar{p}$. It means that the pharmacy's retail 
price cannot exceed the retail price cap. The pharmaceutical manufacturer's profit-maximizing problem is

$$
\operatorname{Max}_{w^{r r}} \pi_{m}\left(w^{r r}\right)=\left(w^{r r}-c\right)\left[\alpha-(\beta-\gamma)\left(p_{1}^{r r}+p_{2}^{r r}\right)\right] .
$$

The pharmacy's profit-maximizing problem is

$$
\begin{aligned}
& \operatorname{Max}_{1}^{r r}, p_{2}^{r r} \pi_{r}\left(p_{1}^{r r}, p_{2}^{r r}\right)=\left(p_{1}^{r r}-w^{r r}-c_{1}\right) d_{1}^{r r}+\left(p_{2}^{r r}-w^{r r}-c_{2}\right) d_{2}^{r r} \\
& \text { s.t. } \quad p^{r r} \leq \bar{p} .
\end{aligned}
$$

(iv) RL model:in a RL model, the government regulates both the upstream pharmaceutical manufacturer and the downstream pharmacy and $\phi$ is the linkage coefficient to maintain a connection between the two price caps, $\bar{w}=\phi \bar{p}$. The purpose of this linkage price cap regulation is to regulate the entire supply chain, and the pharmaceutical manufacturer's wholesale price and the pharmacy's retail price will be constrained by price cap. The pharmaceutical manufacturer's profitmaximizing problem is

$$
\underset{w^{r l}}{\operatorname{Max}} \pi_{m}\left(w^{r l}\right)=\left(w^{r l}-c\right)\left[\alpha-(\beta-\gamma)\left(p_{1}^{r l}+p_{2}^{r l}\right)\right] \text {. }
$$

The pharmacy's profit-maximizing problem is

$$
\begin{aligned}
& \operatorname{Max}_{1}^{r l}, p_{2}^{r l} \pi_{r}\left(p_{1}^{r l}, p_{2}^{r l}\right)=\left(p_{1}^{r l}-w^{r l}-c_{1}\right) d_{1}^{r l}+\left(p_{2}^{r l}-w^{r l}-c_{2}\right) d_{2}^{r l} \\
& \text { s.t. } \quad w^{r l} \leq \phi \bar{p}, p^{r l} \leq \bar{p} .
\end{aligned}
$$

Now, we can derive the optimal wholesale price $w^{i j}$ and the optimal retail prices $p_{i}^{i j}$ for the RN, RM, RR, and RL models ( $i=1,2, j=\mathrm{RN}, \mathrm{RM}, \mathrm{RR}, \mathrm{RL})$ which are summarized in Table 2. Hence, the pharmaceutical manufacturer's optimal wholesale price and the pharmacy's optimal offline and online retail prices exist and are unique in these price cap models.

Based on the optimal pricing decisions in Table 2, we can derive the optimal profits of the pharmaceutical manufacturer and the pharmacy for the RN, RM, RR, and RL models which are summarized in Table 3.

\section{Effects of Price Cap Regulations}

In this section, we explore how each price cap regulation affects the pharmaceutical manufacturer and the pharmacy by comparing the optimal price decisions, profits, and social welfare under different price cap regulations with those without price cap regulation. In this way, we aim to find which price cap regulation can benefit the pharmaceutical manufacturer and the pharmacy and shed light on how to design price cap regulations for the government.

\subsection{Effect of Price Cap Regulations on Pricing Decisions}

4.1.1. Effect of RM on Pricing Decisions. Referring to the relevant equilibriums in Table 2, we have the wholesale price cap $\bar{w}$, the optimal wholesale price, and the optimal retail prices under the RM model.

Proposition 1. For the $R M$ model, (i) if $\bar{w}>w^{r n}$, then $w^{r m}=w^{r n}, p_{1}^{r m}=p_{1}^{r n}$, and $p_{2}^{r m}=p_{2}^{r n}$ and (ii) if $\bar{w}<w^{r n}$, then $w^{r m}<w^{r n}, p_{1}^{r m}=p_{1}^{r n}$, and $p_{2}^{r m}=p_{2}^{r n}$.

Please see Proposition 1 of Appendix.

Proposition 1 discusses that when the government has a wholesale price cap regulation on the pharmaceutical manufacturer, there are two situations. Part (i) of this proposition shows that if the wholesale price cap is higher than the optimal unregulated wholesale price $\left(\bar{w}>w^{r n}\right)$, the optimal wholesale price and retail prices will equal those for the $\mathrm{RN}$ model. It means that the pharmaceutical manufacturer's price cap regulation has no effect on either firm. Part (ii) of this proposition shows that if the wholesale price cap is lower than the optimal unregulated wholesale price $\left(\bar{w}<w^{r n}\right)$, the optimal wholesale price will be lower than that for the RN model, and the offline and online retail prices will equal those for the $\mathrm{RN}$ model. Thus, in this situation, the pharmacy's optimal offline and online retail prices remain unchanged.

4.1.2. Effect of $R R$ on Pricing Decisions. Referring to the relevant equilibriums in Table 2, we have the retail price cap $\bar{p}$, the optimal wholesale price, and the optimal retail prices under the RR model.

Proposition 2. For the RR model, (i) if $\bar{p}>p_{1}^{r n}$, then $W^{r r}=$ $W^{r n} p_{1}^{r r}=p_{1}^{r n}$, and $p_{2}^{r r}=p_{2}^{r n}$; (ii) if $p_{2}^{r n}<\bar{p}<p_{1}^{r n}$, then $w^{r r}>w^{r n}, p_{1}^{r r}<p_{1}^{r n}$, and $p_{2}^{r r}=p_{2}^{r n} p_{2}^{r r}=p_{2}^{r n}$; and (iii) if $\bar{p}<p_{2}^{r n}$, then $w^{r r}>w^{r n}, p_{1}^{r r}<p_{1}^{r n}$, and $p_{2}^{r r}<p_{2}^{r n}$.

Please see Proposition 2 of Appendix.

Proposition 2 shows that when the government has a retail price cap regulation on the pharmacy, there are three situations. Part (i) of this proposition shows that if the retail price cap is higher than the optimal unregulated offline retail price $\left(\bar{p}>p_{1}^{r n}\right)$, the wholesale price and offline and online retail prices will be equal to those for the $\mathrm{RN}$ model. It means that the pharmaceutical manufacturer's price cap regulation has no effect on the pharmaceutical manufacturer and pharmacy.

Part (ii) of this proposition shows that if the retail price cap is lower than the optimal unregulated offline retail price and higher than the optimal unregulated online retail price $\left(p_{2}^{r n}<\bar{p}<p_{1}^{r n}\right)$, the optimal wholesale price will be higher than the optimal unregulated wholesale price. The optimal offline retail price will be lower than the optimal unregulated offline retail price and the optimal online retail price will equal the optimal unregulated online retail price. This is because a lower retail price stimulates consumer demand and the pharmaceutical manufacturer will charge a higher wholesale price for profit-maximizing. 
TABLE 2: Optimal wholesale and retail prices for the four models.

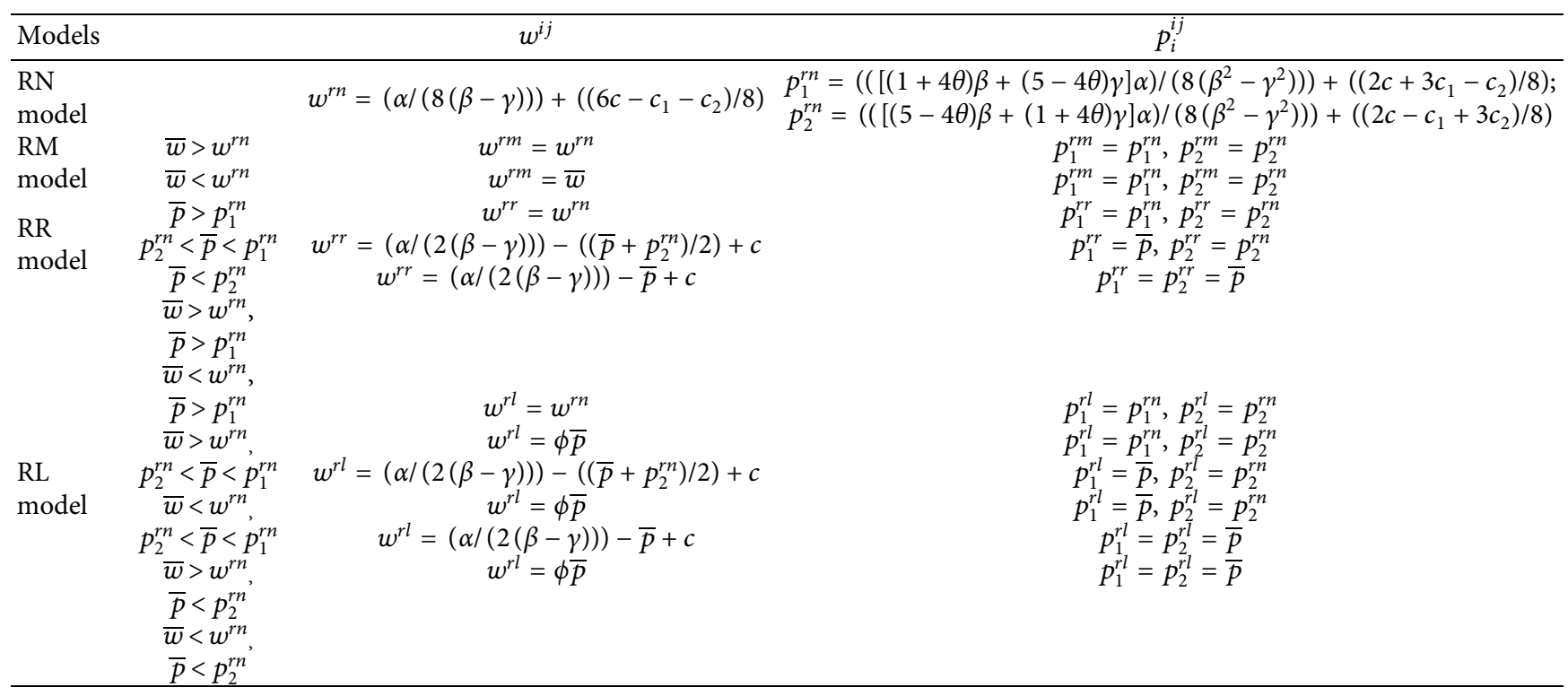

Part (iii) of this proposition indicates that if the retail price cap is lower than the optimal unregulated online retail price $\left(\bar{p}<p_{2}^{r n}\right)$, the optimal wholesale price will be higher than those for the RN model. The explanation is similar to part (ii) of this proposition. The optimal offline and online retail prices will equal the retail price cap, lower than those for the RN model.

\subsubsection{Effect of RL on Pricing Decisions}

Proposition 3. For the RL model, (i) if $\bar{w}>w^{r n}$ and $\bar{p}>p_{1}^{r n}$, then $w^{r l}=w^{r n}, p_{1}^{r l}=p_{1}^{r n}$, and $p_{2}^{r l}=p_{2}^{r n}$; (ii) if $\bar{w}<w^{r n}$ and $\bar{p}>p_{1}^{r n}$, then $w^{r l}<w^{r n}, p_{1}^{r l}=p_{1}^{r n}$, and $p_{2}^{r l}=p_{2}^{r n}$; (iii) if $\bar{w}>w^{r n}$ and $p_{2}^{r n}<\bar{p}<p_{1}^{r n}$, then $w^{r l}>w^{r n}, p_{1}^{r l}<p_{1}^{r n}$, and $p_{2}^{r l}=p_{2}^{r n}$; (iv) if $\bar{w}<w^{r n}$ and $p_{2}^{r n}<\bar{p}<p_{1}^{r n}$, then $w^{r l}<w^{r n}$, $p_{1}^{r l}<p_{1}^{r n}$, and $p_{2}^{r l}=p_{2}^{r n}$; (v) if $\bar{w}>w^{r n}$ and $\bar{p}<p_{2}^{r n}$, then $w^{r l}>w^{r n}, p_{1}^{r l}<$, and $p_{2}^{r l}<p_{2}^{r n}$; and (vi) if $\bar{w}<w^{r n}$ and $\bar{p}<p_{2}^{r n}$, then $w^{r l}<w^{r n}, p_{1}^{r l}<p_{1}^{r n}$, and $p_{2}^{r l}<p_{2}^{r n}$.

Please see Proposition 3 of Appendix.

Proposition 3 indicates when the government has a linkage price cap regulation on the pharmaceutical manufacturer and the pharmacy, there are six potential outcomes. If the pharmaceutical manufacturer's wholesale price cap is higher than the optimal unregulated wholesale price and the retail price cap is higher than the optimal unregulated offline retail price $\left(\bar{w}>w^{r n}, \bar{p}>p_{1}^{r n}\right)$, the optimal wholesale price and retail prices will equal those for the $\mathrm{RN}$ model. If the wholesale price cap is lower than the optimal unregulated wholesale price and the retail price cap is higher than the optimal unregulated offline retail price $\left(\bar{w}<w^{r n}, \bar{p}>p_{1}^{r n}\right)$, this linkage price cap regulation only affects the pharmaceutical manufacturer. This is the same as the second case where the government has a price cap regulation on the pharmaceutical manufacturer. If the wholesale price cap is higher than the optimal unregulated wholesale price and the retail price cap is situated between the two channels $\left(\bar{w}>w^{r n}, p_{2}^{r n}<\bar{p}<p_{1}^{r n}\right)$, this linkage price cap regulation affects the pharmacy only. This is the same as the second case of the government has a price cap regulation on the pharmacy. If the wholesale price cap is higher than the optimal unregulated wholesale price and the retail price cap is lower than the optimal unregulated online retail price $\left(\bar{w}>w^{r n}, \bar{p}<p_{2}^{r n}\right)$, this linkage price cap regulation affects the pharmacy only. And it is the same as the third case where the government imposes a price cap regulation on the pharmacy.

Part (iv) of this proposition shows that if the wholesale price cap is lower than the optimal unregulated wholesale price and the retail price cap is situated between the two channels $\left(\bar{w}<w^{r n}, p_{2}^{r n}<\bar{p}<p_{1}^{r n}\right)$, the optimal wholesale price will equal the wholesale price cap and the offline retail price will equal the retail price cap, lower than those for $\mathrm{RN}$ model. And the optimal online retail price will equal the optimal unregulated online retail price. Part (vi) shows that if the wholesale price cap is lower than the optimal unregulated wholesale price and the retail price cap is lower than the optimal unregulated online retail price $\left(\bar{w}<w^{r n}, \bar{p}<p_{2}^{r n}\right)$, the optimal wholesale price and retail prices of two channels will be lower than those for the $\mathrm{RN}$ model.

\subsection{Effect of Price Cap Regulations on Profits}

4.2.1. Effect of RM on Profits. In this subsection, we examine the effect of the wholesale price cap on the profits of the pharmaceutical manufacturer and the pharmacy.

Proposition 4. For the RM model, (i) if $\bar{w}>w^{r n}$, then $\pi_{m}^{r m}=\pi_{m}^{r n}, \pi_{r}^{r m}=\pi_{r}^{r n}$, and $\pi^{r m}=\pi^{r n}$ and (ii) if $\bar{w}<w^{r n}$, then $\pi_{m}^{r m}<\pi_{m}^{r n}, \pi_{r}^{r m}>\pi_{r}^{r n}$, and $\pi^{r m}=\pi^{r n}$.

Please see Proposition 4 of Appendix.

Part (i) of this proposition shows that if the wholesale price cap is higher than the optimal unregulated wholesale price $\left(\bar{w}>w^{r n}\right)$, the profits of the pharmaceutical manufacturer, the pharmacy, and the supply chain will equal those 


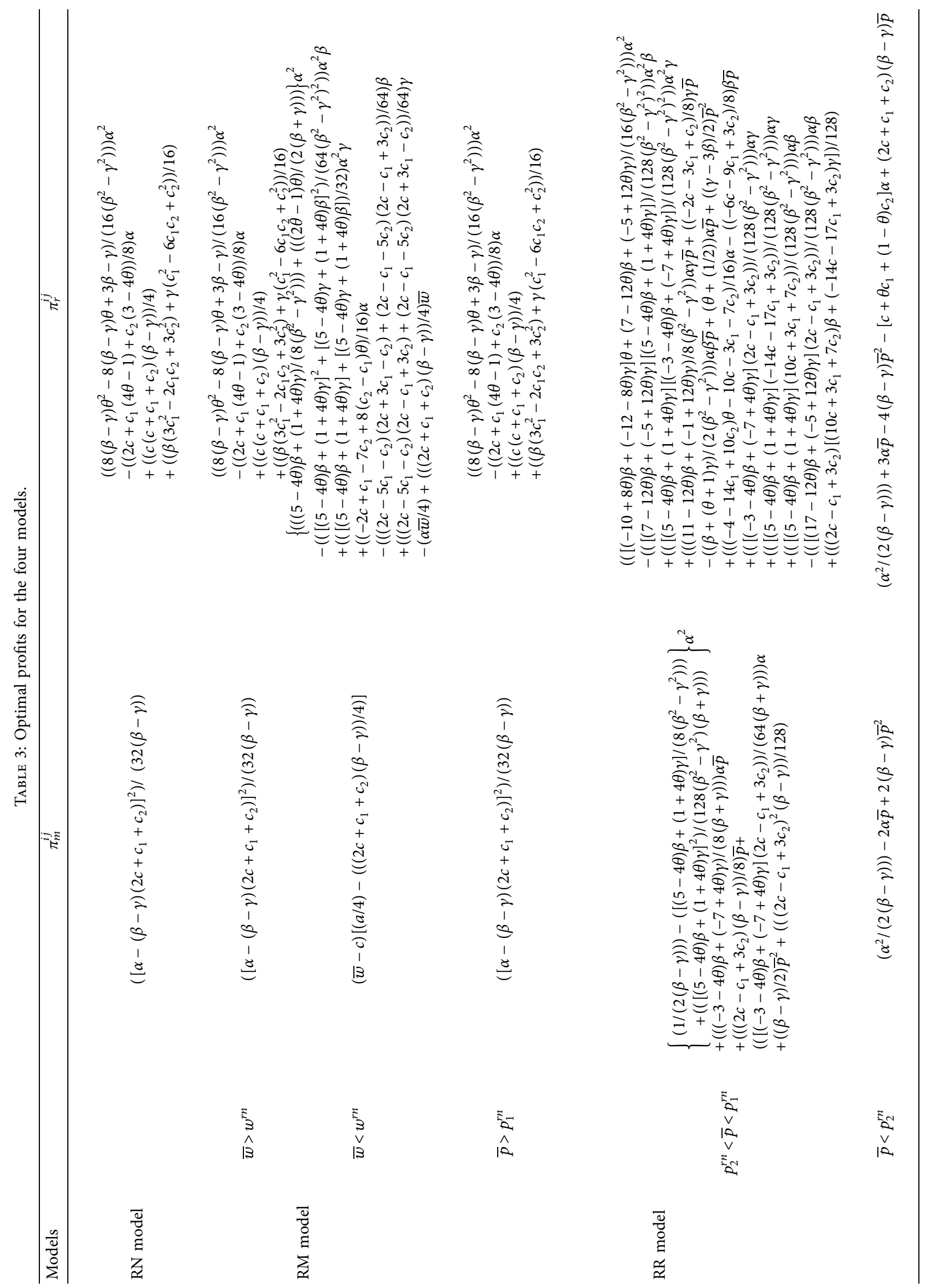




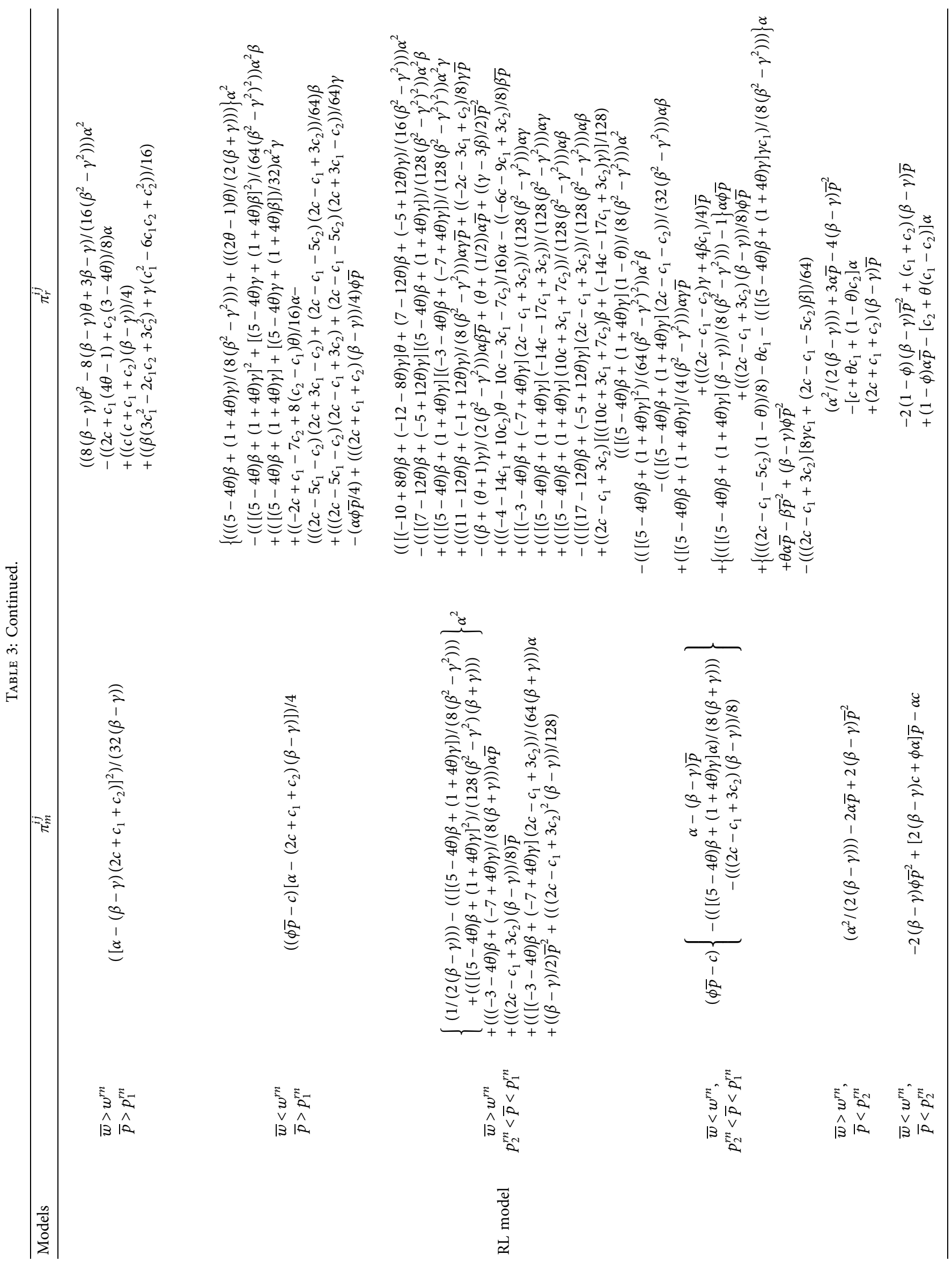


for the RN model. In other words, the pharmaceutical manufacturer's price cap regulation has no effect at all.

Part (ii) of this proposition shows that if the wholesale price cap is lower than the optimal unregulated wholesale price $\left(\bar{w}<w^{r n}\right)$, the pharmaceutical manufacturer's optimal profit will be lower than the optimal unregulated manufacturer's profit. The optimal pharmacy's profit will be higher than the optimal unregulated pharmacy's profit and the optimal supply chain's total profit will equal that for the $\mathrm{RN}$ model. It means that this price cap regulation hurts the pharmaceutical manufacturers' profit but benefits the pharmacy. A lower restricted wholesale price and unchanged demand which is caused by the constant retail price lead to a drop in the pharmaceutical manufacturer's profit. In addition, the rise in the pharmacy's profit can be explained by a lower wholesale price leading to a higher marginal profit. The unchanged profit in the supply chain means that the pharmaceutical manufacturer's reduced profit is exactly equal to the increased profit of the pharmacy; in other words, this price cap regulation has no effect on the profit of the pharmaceutical supply chain. If the pharmaceutical manufacturer is unable to afford the loss caused by the price cap regulation, it may reduce to produce those restricted drugs, leading to a shortage of these regulated drugs in the market. To reduce the risk of the shortage of these regulated drugs, the pharmacy should consider sharing part of the increased profit with the pharmaceutical manufacturer. From the government's point of view, as the policymaker, he should consider subsidizing the pharmaceutical manufacturer, such as subsidizing each unit of drug sold, or increasing investment in technology to fundamentally reduce costs.

4.2.2. Effect of RR on Profits. In Table 3, we have the profits of the pharmaceutical manufacturer and the pharmacy in the RR model. As it is difficult to compare profits analytically, we use numerical examples to illustrate the impacts of the pharmacy price cap regulation. We set $\beta=5, \gamma=3, \alpha=350$, $c_{1}=5, c_{2}=8$, and $c=13$. Consequently, we can have $w^{r n}=30, \quad p_{1}^{r n}=((175(5+2 \theta)) / 16)+(33 / 8), \quad$ and $p_{2}^{r n}=((175(7-2 \theta)) / 16)+(45 / 8)$. In the RR model, the retail price cap is higher than the optimal unregulated online retail price and lower than the optimal unregulated offline retail price without price cap regulation. For convenience, we set $\bar{p}=$ $70\left(p_{2}^{r n} \leq \bar{p} \leq p_{1}^{r n}\right)$. In the same way, when the retail price cap is lower than the optimal online retail price without price cap regulation, we set $\bar{p}=55\left(\bar{p} \leq p_{2}^{r n}\right)$. Because $p_{1}>p_{2}$ is assumed, $\theta>0.7$ is required. Hence, we will only discuss the situation where $0.7<\theta<1$. The profits of the supply chain and its two firms in the RR model are shown in Figures 1-3.

Figures 1-3 illustrate the impacts of the pharmacy price cap regulation on the profits. We can see that if the retail price cap is higher than the optimal unregulated offline retail price $\left(\bar{p}>p_{1}^{r n}\right)$, the profits will be equal to those for the $\mathrm{RN}$ model. If the retail price cap is lower than the optimal unregulated offline retail price $\left(\bar{p}<p_{1}^{r n}\right)$, the profits of the pharmaceutical manufacturer will be higher than those for the RN model. However, the pharmacy's profit will be lower

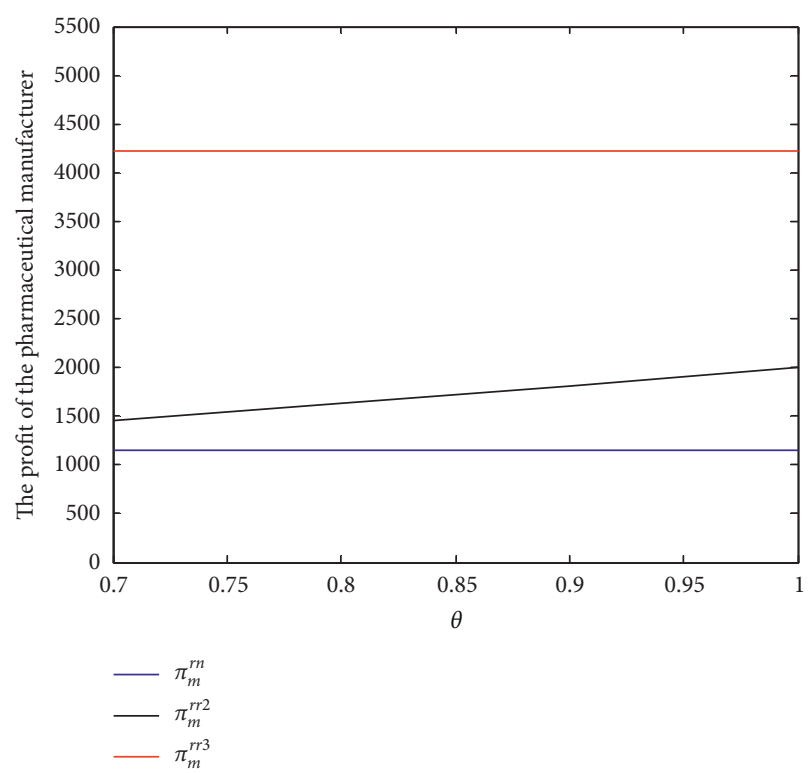

FIgURE 1: The profit of the pharmaceutical manufacturer under retailer price cap regulation.

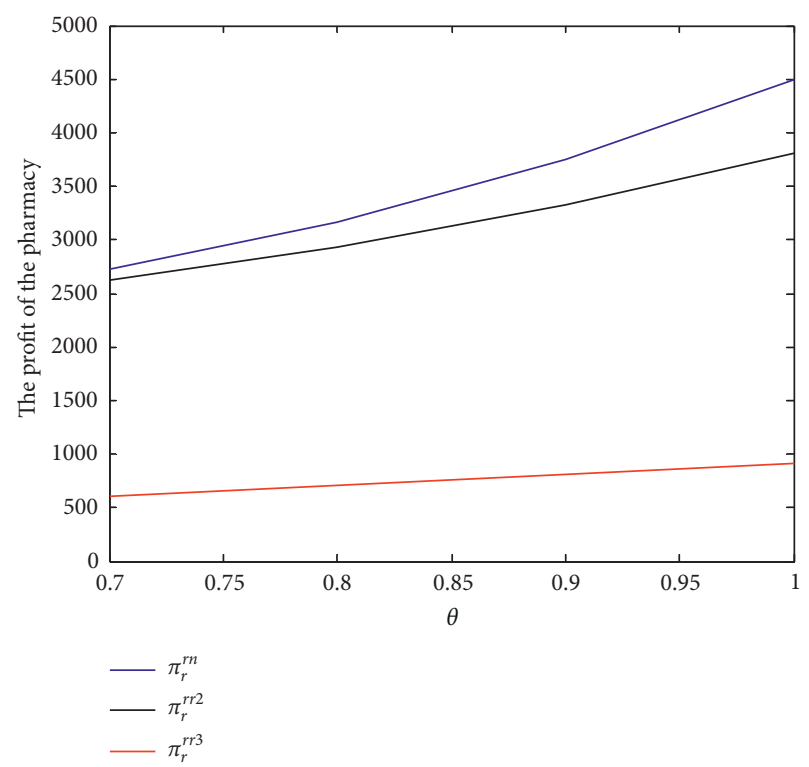

FIgURE 2: The profit of the pharmacy under retailer price cap regulation.

than the unregulated optimal pharmacy's profit. When the retail price cap is very low, the total profit of the supply chain will not always be higher than that without price cap regulation; it depends on the offline market share. For the pharmacy, the increased profit caused by the increased customer demand is insufficient to make up for the loss caused by the decreased marginal profit, thus the price cap regulation has a negative effect on the pharmacy. Hence, it will discourage the pharmacy from supplying the regulated drugs. In this case, the pharmacy may reduce the supply of those regulated drugs and sell those unregulated drugs instead. To avoid this, the pharmaceutical manufacturer 


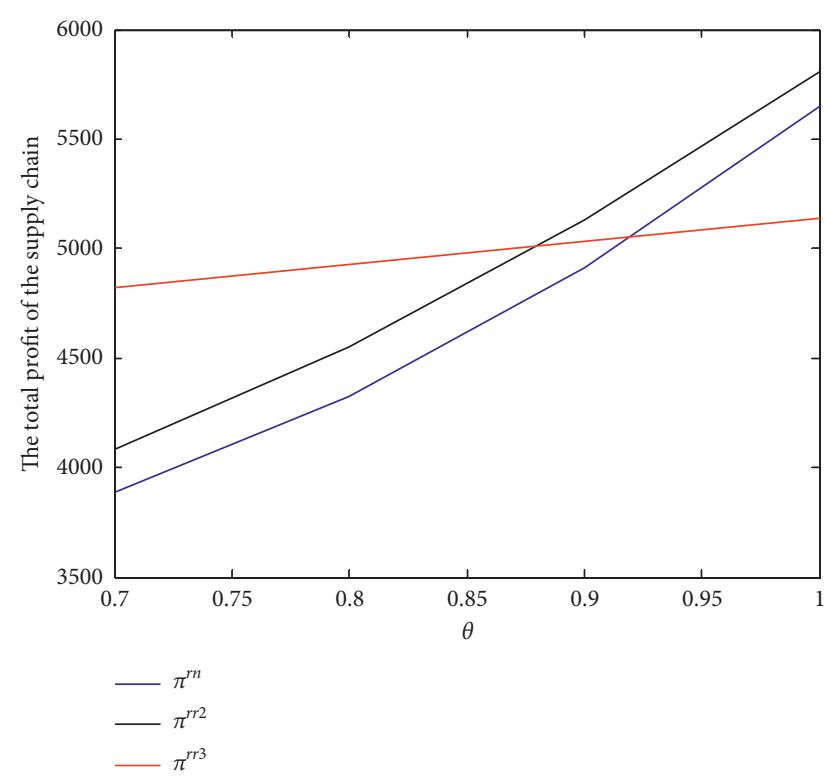

FIgURE 3: The total profit of the supply chain under retailer price cap regulation.

should consider profit sharing with the pharmacy or help the pharmacy integrate its channels. The government, as the policymaker, should take this risk into consideration when formulating this price cap regulation and take measures to help the pharmacy.

4.2.3. Effect of RL on Profits. In Table 3, we have the optimal profits of the pharmaceutical manufacturer and the pharmacy in the RL model. We use numerical examples to illustrate how the linkage price cap regulation affects profits. When the wholesale price cap is lower than the optimal unregulated wholesale price and the retail price cap is situated between the two channels $\left(\bar{w}<w^{r n}, p_{2}^{r n}<\bar{p}<p_{1}^{r n}\right)$, we set $\bar{p}=70$ and $c<\phi \bar{p}<w^{r n}$, so $(13 / 70)<\phi<(3 / 7)$ is required. Hence, here we will only discuss the situation where $0.7<\theta<1$ and $(13 / 70)<\phi<(3 / 7)$. When the wholesale price cap is lower than the optimal unregulated wholesale price and the retail price cap is lower than the optimal unregulated online retail price $\left(\bar{w}<w^{r n}, \bar{p}<p_{2}^{r n}\right)$, we set $\bar{p}=$ 55 and $c<\phi \bar{p}<w^{r n}$, so $(13 / 55)<\phi<(6 / 11)$ is required. Hence, we will only discuss the situation where $0.7<\theta<1$ and $(13 / 55)<\phi<(6 / 11)$. The profits in the RL model are plotted in Figures 4-6.

Figures 4-6 discuss the impacts of the linkage price cap regulation. For brevity, we focus on the situation where both the wholesale price cap and the retail price cap are imposed.

If the wholesale price cap is lower than the optimal unregulated wholesale price and the retail price cap is situated between the two channels $\left(\bar{w}<w^{r n}, p_{2}^{r n}<\bar{p}<p_{1}^{r n}\right)$, the profits of the pharmaceutical manufacturer and the pharmacy will depend on the linkage coefficient and the offline market share. And the linkage coefficient has a greater impact on the pharmaceutical manufacturer's profit. When the linkage coefficient and offline market share are very high, the profits of the pharmaceutical manufacturer and the pharmacy will be higher (lower) than that for the RN model, respectively. A higher linkage coefficient means a higher wholesale price, leading to a higher marginal profit for the pharmaceutical manufacturer. Moreover, a higher offline market share may stimulate more customer demand. Therefore, the pharmaceutical manufacturer's profit increases. For the pharmacy, its marginal profit will decrease due to a higher linkage coefficient, and a higher offline marker share will cause a decreased profit from the offline channel. Therefore, its profit will be lower than that for the $\mathrm{RN}$ model. The profit of the pharmaceutical supply chain in this case will be higher than that in the RN model.

If the wholesale price cap is lower than the optimal unregulated wholesale price and the retail price cap is lower than the optimal online retail price $\left(\bar{w}<w^{r n}, \bar{p}<p_{2}^{r n}\right)$, the pharmaceutical manufacturer's profit only depends on the linkage coefficient. When the linkage coefficient is high, the pharmaceutical manufacturer's profit will be higher than the unregulated pharmaceutical manufacturer's profit. For the pharmacy, when the linkage coefficient and the offline market share are large, its profit will be lower than that for the RN model. The reason is similar to the above. For the supply chain, when the offline market share is high, its profit will be lower than the unregulated optimal supply chain's profit. When the offline market share is low, the optimal profit will be higher than the unregulated optimal supply chain's profit. Thus, the offline market share has a dominant impact on the whole supply chain's profit.

\subsection{Effect of Price Cap Regulation on Social Welfare}

4.3.1. Effect of RM on Social Welfare. In this subsection, we examine the effect of the wholesale price cap on social welfare.

Proposition 5. For the RM model, (i) if $\bar{w}>w^{r n}$, then $W^{r m}=$ $W^{r n}$ and (ii) if $\bar{w}<w^{r n}$, then $W^{r m}=W^{r n}$.

Please see Proposition 5 of Appendix.

This proposition shows that when the government has a wholesale price cap on the pharmaceutical manufacturer, the optimal social welfare will equal that without price cap regulation. It means that the pharmaceutical manufacturer's price cap regulation has no effect on social welfare.

4.3.2. Effect of $R R$ on Social Welfare. In this subsection, we examine the effect of the retail price cap on the social welfare. The social welfare in the RR model is plotted in Figure 7.

Figure 7 shows that when the retail price cap is higher than the optimal unregulated offline retail price $\left(\bar{p}>p_{1}^{r n}\right)$, the optimal social welfare will equal that without price cap regulation. It means that the pharmacy price cap regulation has no effect on the social welfare. Here, we mainly focus on the case where the retail price cap is lower than the optimal offline retail price $\left(\bar{p}<p_{1}^{r n}\right)$. In this case, the optimal social welfare will be higher than that without price cap regulation. As we mentioned above, social welfare consists of the supply chain's profit and patient welfare. Patient welfare depends on offline and online retail prices, and a lower retail price cap 


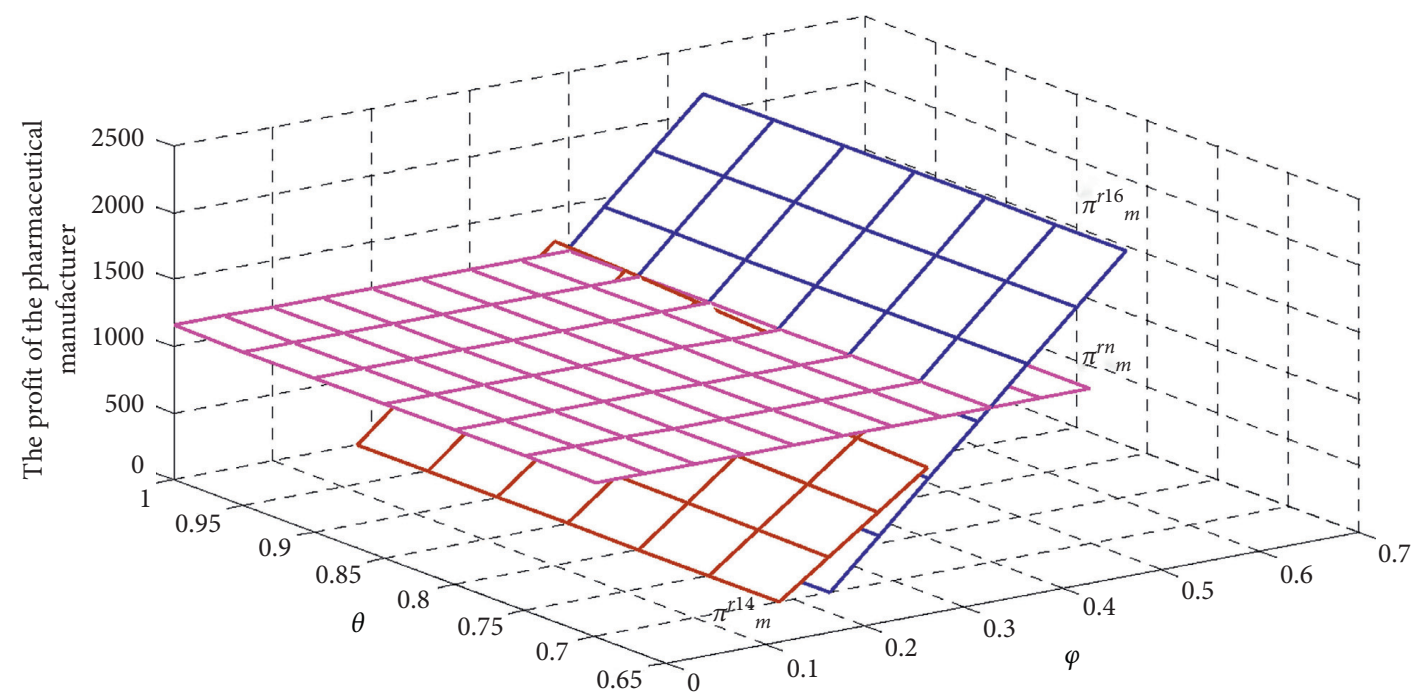

FIgURE 4: The profit of the pharmaceutical manufacturer under linkage price cap regulation.

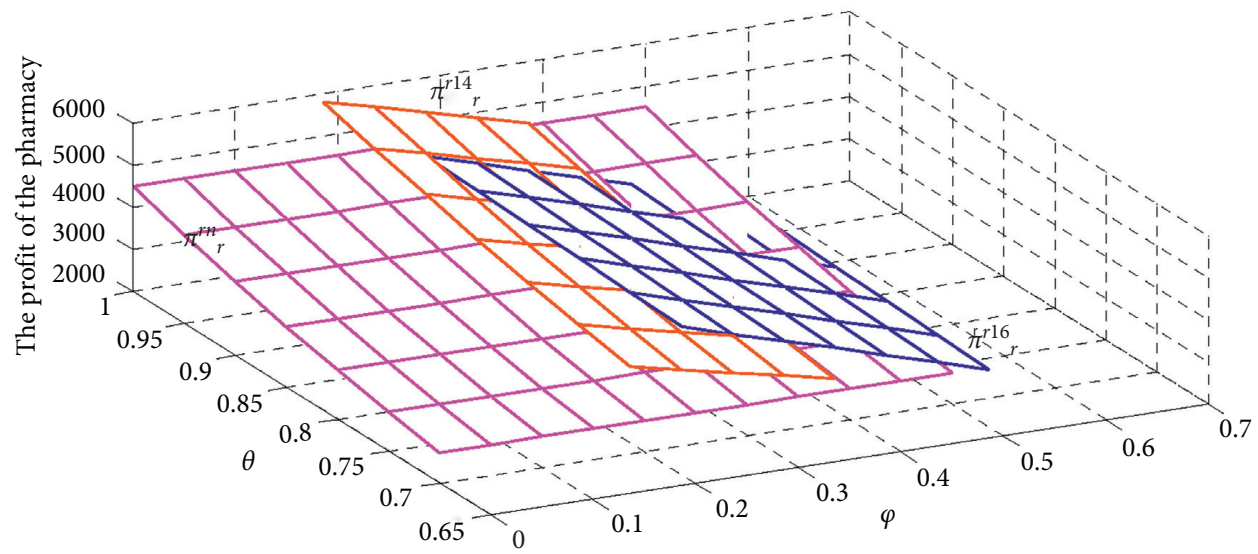

Figure 5: The profit of the pharmacy under linkage price cap regulation.

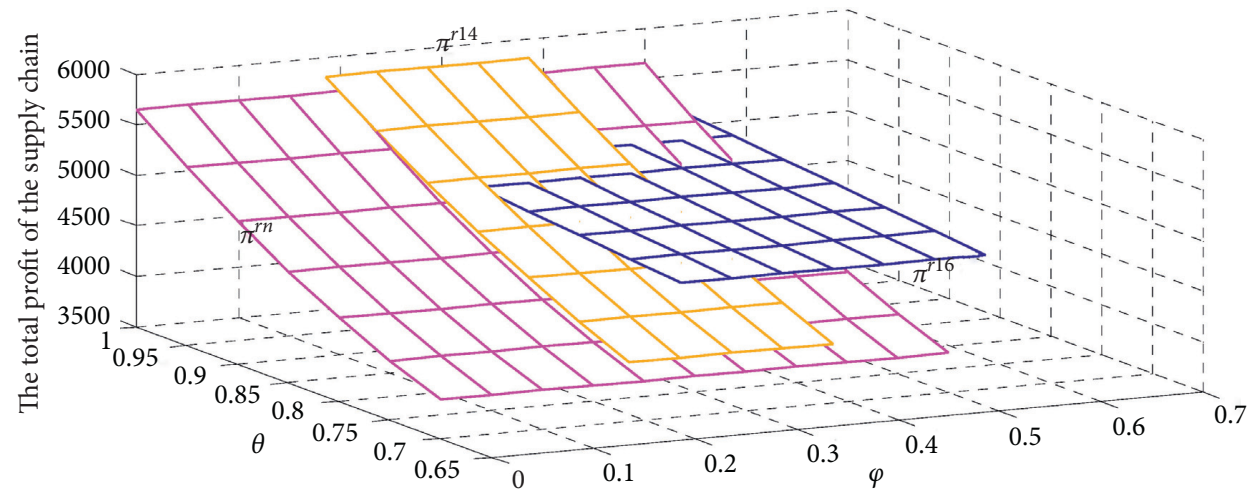

FIGURE 6: The total profit of the supply chain under linkage price cap regulation.

has a positive impact on patient surplus. Moreover, as shown above, when the retail price cap is situated between the optimal unregulated retail prices of the two channels, the supply chain's profit will always be higher than that without price cap regulation. When the retail price cap is very low, the increased patient surplus brought about by a lower retail 


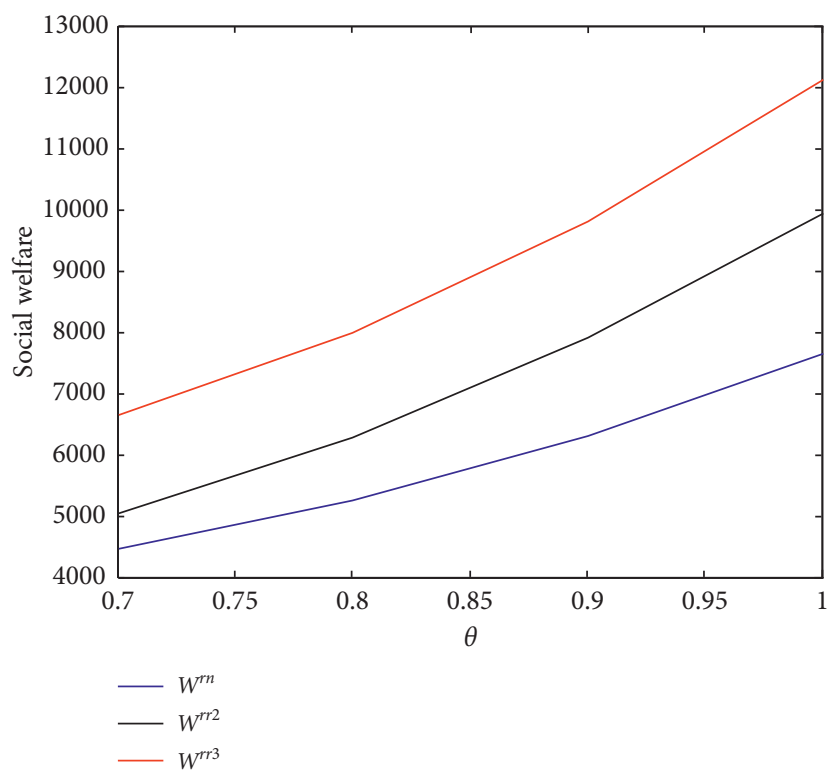

Figure 7: The social welfare under the retailer price cap regulation.

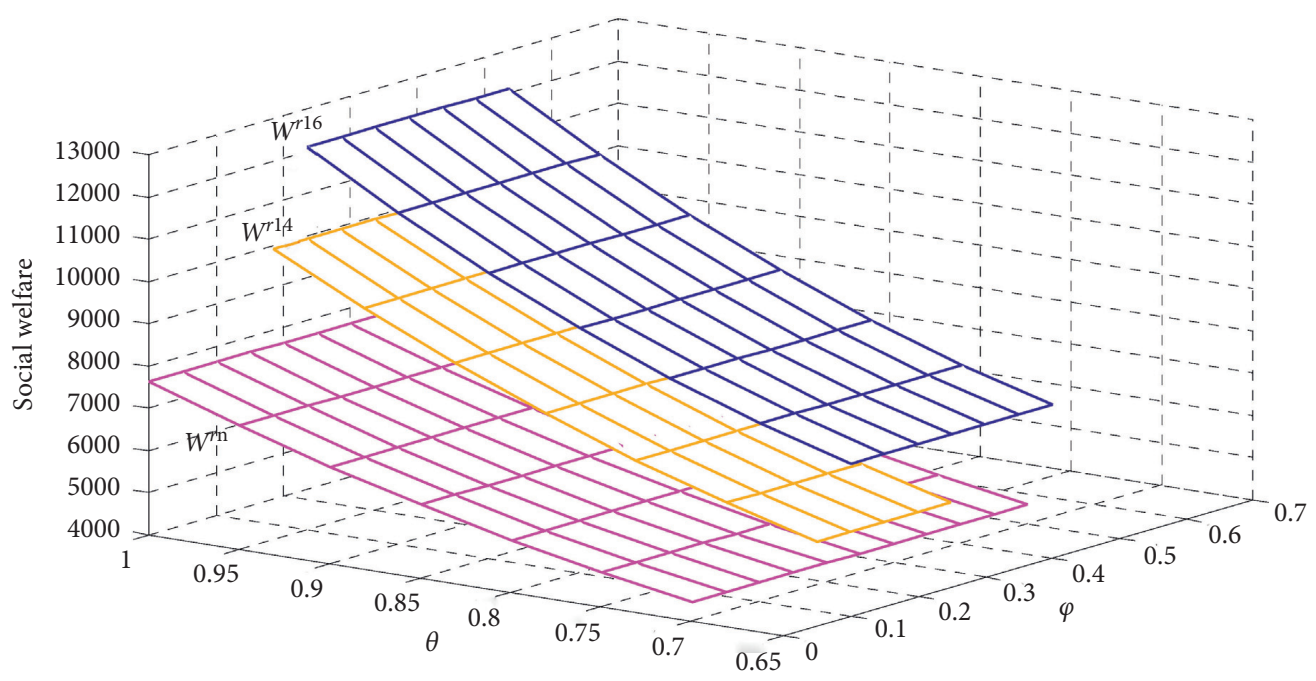

FIGURE 8: Social welfare under linkage price cap regulation.

price is greater than the decreased supply chain's profit. As a result, social welfare will improve when the government implements a lower retail price cap on the pharmacy.

4.3.3. Effect of RL on Social Welfare. In this subsection, we examine the effect of the linkage price cap on social welfare, which is shown in Figure 8.

Figure 8 illustrates the effect of the linkage price cap regulation on social welfare. Here, we focus on the situation where both the wholesale price cap and the retail price cap are imposed.

If the wholesale price cap is lower than the optimal unregulated wholesale price and the retail price cap is situated between the two channels $\left(\bar{w}<w^{r n}, p_{2}^{r n}<\bar{p}<p_{1}^{r n}\right)$, the social welfare will be higher than the optimal unregulated social welfare. This is due to the improved supply chain's profit and patient surplus.

If the wholesale price cap is lower than the optimal unregulated wholesale price and the retail price cap is lower than the optimal online retail price $\left(\bar{w}<w^{r n}, \bar{p}<p_{2}^{r n}\right)$, the social welfare will be higher than the optimal unregulated social welfare. In this case, although the supply chain's profit is lower when the offline market share is low, the increased patient surplus brought about by a lower retail price is greater, resulting in improved social welfare.

\section{Sensitivity Analysis}

In this section, we discuss the impacts of the offline market share and the linkage coefficient on the pricing and profits. 
Proposition 6. In the $R N$ model, $p_{1}^{r n}$ and $\pi_{r}^{r n}$ increase in $\theta$; $p_{2}^{r n}$ decreases in $\theta$; and $w^{r n}$ and $\pi_{m}^{r n}$ are independent on $\theta$.

Please see Proposition 6 of Appendix.

Proposition 6 shows that if the offline market share is larger, the offline retail price will be higher, and the online retail price will be lower. It means that when a company or a channel has a larger market share, it is more likely to set a higher price. In addition, an interesting result here is that the manufacturer's wholesale price and profit are not affected by the offline market share. In other words, the manufacturer's wholesale price depends on its own cost and its profit depends on its marginal profit and market demand. And the channel competition of the pharmacy will not affect the pharmaceutical manufacturer. However, for the pharmacy, the increase in offline market share always has a positive impact on its profit. This is because the marginal profit generated from the offline channel is greater than that from the online channel. It means that the more patients prefer physical drugstores, the higher the pharmacy's profit.

Proposition 7. In the RL model, if $\phi \bar{p}<w^{r n}, \pi_{m}^{r l}$ decreases in $\phi$ and $\pi_{r}^{r l}$ increases in $\phi$.

Please see Proposition 7 of Appendix.

Proposition 7 finds that the higher linkage coefficient hurts the pharmaceutical manufacturer but benefits the pharmacy. A higher linkage coefficient means a lower wholesale price, which is detrimental to the pharmaceutical manufacturer. On the contrary, a lower wholesale price leads to a lower cost of the pharmacy, benefiting the pharmacy.

\section{Conclusions and Future Research}

This paper investigates a two-echelon pharmaceutical supply chain consisting of one pharmaceutical manufacturer and one pharmacy with online and offline channels. We analyzed the impacts of price cap regulations on the pricing decisions, profits, and social welfare of the supply chain and its firms. This is achieved by comparing the pricing decisions, profits, and social welfare under different price cap regulations with those under no price cap regulation.

Our finding shows that regardless of the price cap regulation type, a higher price cap set by the government may have no effect on the pricing decisions, the profits, and social welfare of the supply chain and its firms. If the government sets a lower wholesale price cap, social welfare will remain unchanged. And if the government sets a lower retail price cap or linkage price cap, social welfare will increase.

Like the single-channel supply chain, when the government has one-sided price cap regulations on the pharmaceutical supply chain's firms, the profit of the regulated firm will decrease, and the profit of the unregulated firm will increase. In this case, if the regulated firm cannot bear the loss caused by the price cap regulation, it may reduce the production of those regulated dugs and even completely withdraw from the market, causing a shortage of these regulated drugs in the market.
Therefore, the unregulated firm should consider profit sharing with the regulated firm. In addition, as a policymaker, the government should consider how to subsidize the regulated firm.

When the government implements the linkage price cap regulation and when only the wholesale price cap is imposed, its effects on the pharmaceutical manufacturer and the pharmacy are the same as those in the RM model. Similarly, when only the retail price cap is imposed, its effects on the pharmaceutical manufacturer and the pharmacy are the same to those in the RR model. In addition, we find that when the retail price and wholesale price caps are both imposed, the profits of the pharmaceutical manufacturer and the pharmacy will depend on the linkage coefficient and the offline market share. When both are high, the pharmaceutical manufacturer's profit will rise, and the linkage coefficient has a greater impact on the pharmaceutical manufacturer's profit. When the linkage coefficient is high and the offline market share is low, the pharmacy's profit will increase. Therefore, both firms are more willing to accept the linkage price cap regulation if the government sets a higher linkage coefficient. In general, the drug price cap regulation is an effective measure for the government to carry out macrocontrol of the pharmaceutical market and to balance the market supply and patient demand.

There are several potential limitations to this research. For example, we only consider deterministic but not stochastic demand. In addition, our paper only considers one manufacturer and one retailer with online and offline channels. However, there may be multiple manufacturers and retailers in pharmaceutical supply chains. Thus, first, future research can consider stochastic demand and multiple manufacturers and retailers. Second, future research can consider more complex pharmaceutical supply chains and their disruptions [42, 43], and the roles of corporate social responsibility [44] and fairness concerns [45].

\section{Appendix}

\section{Proof of Table 2}

$R N$ model. Based on (3), we get $\left(\left(\mathrm{d} \pi_{m}\left(w^{r n}\right)\right) / \mathrm{d} w^{r n}\right)=\alpha-$ $(\beta-\gamma)\left(m_{1}+m_{2}-2 c+4 w^{r n}\right)$ and $\left(\left(\mathrm{d}^{2} \pi_{m}\left(w^{r n}\right)\right) / \mathrm{d} w^{r n 2}\right)=$ $-4(\beta-\gamma)<0$. So $\pi_{m}\left(w^{r n}\right)$ is concave in $w$. From $\left(\left(\mathrm{d} \pi_{m}\left(w^{r n}\right)\right) / \mathrm{d} w^{r n}\right)=0$, we get $w^{r n}=(\alpha /(2(\beta-\gamma)))-$ $\left(\left(p_{1}^{r n}+p_{2}^{r n}\right) / 2\right)+c$. Replacing $w^{r n}$ in (5), we get $\left(\left(\partial \pi_{r}\left(p_{1}^{r n}, p_{2}^{r n}\right)\right) / \partial p_{1}^{r n}\right)=(3 / 2)\left(\theta \alpha-\beta p_{1}^{r n}+\gamma p_{2}^{r n}\right)+\left(\left(\left(3 p_{1}^{r n}+\right.\right.\right.$ $\left.\left.\left.p_{2}^{r n}\right) / 2\right)-(\alpha /(2(\beta-\gamma)))-c-c_{1}\right)(-\beta)+(1 / 2)[(1-\theta) \alpha-\beta$ $\left.p_{2}^{r n}+\gamma p_{1}^{r n}\right]+\left(\left(\left(3 p_{2}^{r n}+p_{1}^{r n}\right) / 2\right)-(\alpha /(2(\beta-\gamma)))-c-c_{2}\right) \gamma$ and $\left(\left(\partial^{2} \pi_{r}\left(p_{1}^{r n}, p_{2}^{r n}\right)\right) / \partial p_{1}^{r n 2}\right)=-(3 \beta-\gamma)<0 . \quad\left(\left(\partial \pi_{r}\left(p_{1}^{r n}, p_{2}^{r n}\right)\right) /\right.$ $\left.\partial p_{2}^{r n}\right)=(1 / 2)\left(\theta \alpha-\beta p_{1}^{r n}+\gamma p_{2}^{r n}\right)+\left(\left(\left(3 p_{1}^{r n}+p_{2}^{r n}\right) / 2\right)-(\alpha /(2\right.$ $\left.(\beta-\gamma)))-c-c_{1}\right) \gamma+(3 / 2)\left[(1-\theta) \alpha-\beta p_{2}^{r n}+\gamma p_{1}^{r n}\right]+\left(\left(\left(3 p_{2}^{r n}+\right.\right.\right.$ $\left.\left.\left.p_{1}^{r n}\right) / 2\right)-(\alpha /(2(\beta-\gamma)))-c-c_{2}\right)(-\beta) \quad\left(\left(\partial^{2} \pi_{r}\left(p_{1}^{r n}, \quad p_{2}^{r n}\right)\right) / \partial\right.$ $\left.p_{2}^{r n 2}\right)=-(3 \beta-\gamma)<0$ and $\left(\left(\partial^{2} \pi_{r}\left(p_{1}^{r n}, p_{2}^{r n}\right)\right) / \partial p_{1}^{r n} p_{2}^{r n}\right)=$ $\left(\left(\partial^{2} \pi_{r}\left(p_{1}^{r n}, p_{2}^{r n}\right)\right) / \partial p_{2}^{r n} p_{1}^{r n}\right)=3 \gamma-\beta$.

There is a Hessian Matrix $\left(\left(\partial^{2} \pi_{r}\left(p_{1}^{r n}, p_{2}^{r n}\right)\right) / \partial\right.$ $\left.p_{1}^{r n} 2 \partial^{2} \pi_{r}\left(p_{1}^{r n}, p_{2}^{r n}\right)\right) / \partial p_{1}^{r n} p_{2}^{r n}\left(\partial^{2} \pi_{r}\left(p_{1}^{r n}, p_{2}^{r n}\right)\right) / \partial p_{2}^{r r} p_{1}^{r n}\left(\partial^{2} \pi_{r}\right.$ $\left.\left.\left(p_{1}^{r n}, p_{2}^{r n}\right)\right) / \partial p_{2}^{r n 2}\right)=8\left(\beta^{2}-\gamma^{2}\right)>0$, so $\pi_{r}\left(p_{1}^{r n}, p_{2}^{r n}\right)$ is joint 
concave in $p_{1}^{r n}$ and $p_{2}^{r n}$. From $\left(\left(\partial \pi_{r}\left(p_{1}^{r n}, p_{2}^{r n}\right)\right) / \partial p_{1}^{r n}\right)=0$ and $\left(\left(\partial \pi_{r}\left(p_{1}^{r n}, p_{2}^{r n}\right)\right) / \partial p_{2}^{r n}\right)=0$, we can get $p_{1}^{r n}=([(1+4 \theta) \beta+$ $\left.(5-4 \theta) \gamma] /\left(8\left(\beta^{2}-\gamma^{2}\right)\right)\right) \alpha+\left(\left(2 c+3 c_{1}-c_{2}\right) / 8\right), p_{1}^{r n}=([(5-$ $\left.4 \theta) \beta+\quad(1+4 \theta) \gamma] /\left(8\left(\beta^{2}-\gamma^{2}\right)\right)\right) \alpha+\left(\left(2 c-\quad c_{1}+3 c_{2}\right) / 8\right)$. Replacing $p_{1}^{r n}$ and $p_{2}^{r n}$ in $w^{r n}$, we get $w^{r n}=(\alpha /(8(\beta-\gamma)))+\left(\left(6 c-c_{1}-c_{2}\right) / 8\right)$.

$R M$ model. In this model, we need to solve $\operatorname{Max}_{w} \pi_{m}\left(w^{r m}\right)=$ $\left(w^{r m}-c\right)\left[\theta \alpha-\beta p_{1}^{r m}+\gamma p_{2}^{r m}\right]+(w-c)\left[(1-\theta) \alpha-\beta p_{2}^{r m}+\right.$

$\gamma p_{1}^{r m}$ ] subject to $w^{r m} \leq \bar{w}$ :

(i) If $\bar{w}>w^{r n}$, the price cap regulation does not work, so the optimal prices are $w^{r m}=w^{r n}$ and $p_{1}^{r m}=p_{1}^{r n}$, $p_{2}^{r m}=p_{2}^{r n}$.

(ii) If $\bar{w}<w^{r n}$, the price cap regulation works; then, for the manufacturer, the optimal wholesale price is $w^{r m}=\bar{w}$; for the retailer, we should solve $\operatorname{Max}_{p_{1}^{r m}, p_{2}^{r m} \pi_{r}}\left(p_{1}^{r m}, p_{2}^{r m}\right)=\left(p_{1}^{r m}-\bar{w}-c_{1}\right)\left[\theta \alpha-\beta p_{1}^{r m}+\right.$ $\left.\gamma p_{2}^{r m}\right]^{1}+\left(p_{2}^{r m}-\bar{w}-c_{2}\right)\left[(1-\theta) \alpha-\beta p_{2}^{r m}+\gamma p_{1}^{r m}\right]$; and we can see easily that the range of retail prices is $w^{r m}<p_{1} \leq p_{1}^{r n}$ and $w^{r m}<p_{2} \leq p_{2}^{r n}$, so $p_{1}^{r m}=p_{1}^{r n}$ and $p_{2}^{r m}=p_{2}^{r n}$.

In summary, if $\bar{w}>w^{r n}$, then $w^{r m}=w^{r n}, p_{1}^{r m}=p_{1}^{r n}$, $p_{2}^{r m}=p_{2}^{r n}$; if $\bar{w}<w^{r n}$, then $w^{r m}=\bar{w}, p_{1}^{r m}=p_{1}^{r n}, p_{1}^{r m}=p_{1}^{r n}$.

$R R$ model. In this model, from the proof of the $\mathrm{RN}$ model, the response function is $w^{r n}=(\alpha /(2(\beta-\gamma)))-\left(\left(p_{1}^{r n}+\right.\right.$ $\left.\left.p_{2}^{r n}\right) / 2\right)+c$, so we need to solve it. $\operatorname{Max}_{p_{1}^{r r}, p_{2}^{r r} \pi_{r}}\left(p_{1}^{r r}, p_{2}^{r r}\right)=$ $\left(p_{1}^{r r}-(\alpha /(2(\beta-\gamma)))+\left(\left(p_{1}^{r r}+p_{2}^{r r}\right) / 2\right)-c-c_{1}\right)\left(\theta \alpha-\beta p_{1}^{r r}\right.$ $\left.+\gamma p_{2}^{r r}\right)+\left(p_{2}^{r r}-(\alpha /(2(\beta-\gamma)))+\left(\left(p_{1}^{r r}+p_{2}^{r r}\right) / 2\right)-c-c_{2}\right)$ $\left[(1-\theta) \alpha-\beta p_{2}^{r r}+\gamma p_{1}^{r r}\right]$ subject to $p_{1}^{r r}, p_{2}^{r r} \leq \bar{p}$ :

(i) If $\bar{p}>p_{1}^{r n}$, the price cap regulation does not work, so the optimal prices are and $w^{r r}=w^{r n}, p_{1}^{r r}=p_{1}^{r n}$, $p_{2}^{r r}=p_{2}^{r n}$.

(ii) If $p_{2}^{r n}<\bar{p}<p_{1}^{r n}$, the price cap regulation works; for the manufacturer, the optimal wholesale price $w^{r r}=(\alpha /(2(\beta-\gamma)))-\left(\left(\bar{p}+p_{2}^{r n}\right) / 2\right)+c$. Then, for the pharmacy, the optimal retail prices are $p_{1}^{r r}=\bar{p}$, $p_{2}^{r r}=p_{2}^{r n}$.

(iii) If $\bar{p}<p_{2}^{r n}$, the price cap regulation works and the retail prices of the two channels are regulated, so the optimal retail prices are $p_{1}^{r r}=p_{2}^{r r}=\bar{p}$. Replace $\bar{p}$ in $w^{r n}=(\alpha /(2(\beta-\gamma)))-\left(\left(p_{1}^{r n}+p_{2}^{r n}\right) / 2\right)+c ; \quad$ then $w^{r r}=(\alpha /(2(\beta-\gamma)))-\bar{p}+c$.

In summary, if $\bar{p}>p_{1}^{r n}$, then $w^{r r}=w^{r n}, p_{1}^{r r}=p_{1}^{r n}$, $p_{2}^{r r}=p_{2}^{r n}$; if $p_{2}^{r n}<\bar{p}<p_{1}^{r n}$, then $w^{r r}=(\alpha /(2(\beta-\gamma)))-((\bar{p}+$ $\left.\left.p_{2}^{r n}\right) / 2\right)+c, \quad p_{1}^{r r}=\bar{p}, \quad p_{2}^{r r}=p_{2}^{r n}$; if $\bar{p}<p_{2}^{r n}$, then $w^{r r}=$ $(\alpha /(2(\beta-\gamma)))-\bar{p}+c, p_{1}^{r r}=p_{2}^{r r}=\bar{p}$.

\section{$R L$ model}

(i) If $\bar{w}>w^{r n}, \bar{p}>p_{1}^{r n}$, the linkage price cap regulation has no effect on the manufacturer and the pharmacy, so $w^{r l}=w^{r n}, p_{1}^{r l}=p_{1}^{r n}, p_{2}^{r l}=p_{2}^{r n}$.

(ii) If $\bar{w}<w^{r n}, \bar{p}>p_{1}^{r n}$, the linkage price cap regulation only has an effect on the manufacturer; from (ii) of the RN model, we obtain $w^{r l}=\bar{w}=\phi \bar{p}$ and $p_{1}^{r l}=p_{1}^{r n}, p_{2}^{r l}=p_{2}^{r n}$.

(iii) If $\bar{w}>w^{r n}, p_{2}^{r n}<\bar{p}<p_{1}^{r n}$, the linkage price cap regulation only has an effect on the pharmacy; from (ii) of the RR model, we obtain $w^{r l}=(\alpha /(2(\beta-\gamma)))-$ $\left(\left(\bar{p}+p_{2}^{r n}\right) / 2\right)+c$ and $p_{1}^{r l}=\bar{p}, p_{2}^{r l}=p_{2}^{r n}$.

(iv) If $\bar{w}<w^{r n}, p_{2}^{r n}<\bar{p}<p_{1}^{r n}$, the linkage price cap regulation has an effect on the manufacturer and pharmacy. We can easily get $w^{r l}=\bar{w}=\phi \bar{p}, p_{1}^{r l}=\bar{p}$, $p_{2}^{r l}=p_{2}^{r n}$.

(v) If $\bar{w}>w^{r n}, \bar{p}<p_{2}^{r n}$, the linkage price cap regulation only has an effect on the pharmacy; from (iii) of the RR model, we obtain $w^{r l}=(\alpha /(2(\beta-\gamma)))-\bar{p}+c$, $p_{1}^{r l}=p_{2}^{r l}=\bar{p}$.

(vi) If $\bar{w}<w^{r n}, \bar{p}<p_{2}^{r n}$, the linkage price cap regulation has an effect on the manufacturer and pharmacy. We can easily get $w^{r l}=\bar{w}=\phi \bar{p}, p_{1}^{r l}=p_{2}^{r l}=\bar{p}$.

In summary, if $\bar{w}<w^{r n}, \bar{p}>p_{1}^{r n}$, then $w^{r l}=w^{r n}$, $p_{1}^{r l}=p_{1}^{r n}, p_{2}^{r l}=p_{2}^{r n}$; if $\bar{w}<w^{r n}, \bar{p}>p_{1}^{r n}$, then $w^{r l}=\bar{w}=\phi \bar{p}$, $p_{1}^{r l}=p_{1}^{r n}, \quad p_{2}^{r l}=p_{2}^{r n} ; \quad$ if $\quad \bar{w}>w^{r n}, \quad p_{2}^{r n}<\bar{p}<p_{1}^{r n}$, then $w^{r l}=(\alpha /(2(\beta-\gamma)))-\left(\left(\bar{p}+p_{2}^{r n}\right) / 2\right)+c, p_{1}^{r l}=\bar{p}, p_{2}^{r l}=p_{2}^{r n}$; if $\bar{w}<w^{r n}, \quad p_{2}^{r n}<\bar{p}<p_{1}^{r n}$, then $w^{r l}=\bar{w}=\phi \bar{p}, \quad p_{1}^{r l}=\bar{p}$, $p_{2}^{r l}=p_{2}^{r n} ; \quad$ if $\bar{w}>w^{r n}, \bar{p}<p_{2}^{r n}$, then $w^{r l}=(\alpha /)(2(\beta-$ $\gamma)))-\bar{p}+c, p_{1}^{r l}=\bar{p}, p_{2}^{r l}=p_{2}^{r n}$; if $\bar{w}<w^{r n}, \bar{p}<p_{2}^{r n}$, then $w^{r l}=\bar{w}=\phi \bar{p}, p_{1}^{r l}=p_{2}^{r l}=\bar{p}$.

Proof of Proposition 1. (i) From Table 2, if $\bar{w}>w^{r n}$, then $w^{r m}=w^{r n}$ and $p_{1}^{r m}=p_{1}^{r n}, p_{2}^{r m}=p_{2}^{r n}$ and (ii) if $\bar{w}<w^{r n}$, then $w^{r m}-w^{r n}=\bar{w}-w^{r n}<0$, so $w^{r m}<w^{r n}$. From Table 2, obviously $p_{1}^{r m}=p_{1}^{r n}, p_{2}^{r m}=p_{2}^{r n}$.

Proof of Proposition 2. From Table 2, (i) if $\bar{p}>p_{1}^{r n}$, then $w^{r r}=w^{r n}$ and $p_{1}^{r r}=p_{1}^{r n}, p_{2}^{r r}=p_{2}^{r n}$. (ii) If $p_{2}^{r n}<\bar{p}<p_{1}^{r n}$, then $w^{r r}-w^{r n}=\left(\left(p_{1}^{r n}-\bar{p}\right) / 2\right)>0, \quad p_{1}^{r r}-p_{1}^{r n}=\bar{p}-p_{1}^{r n}<0, \quad$ so $w^{r r}>w^{r n}, p_{1}^{r r}<p_{1}^{r n}$; in addition, from Table $2, p_{2}^{r r}=p_{2}^{r n}$. (iii) If $\bar{p}<p_{2}^{r n}$, then $w^{r r}-w^{r n}=\left(\left(p_{1}^{r n}+p_{2}^{r n}-2 \bar{p}\right) / 2\right)>0$, so $w^{r r}>w^{r n}$. And $p_{1}^{r r}-p_{1}^{r n}=\bar{p}-p_{1}^{r n}<0, p_{2}^{r r}-p_{2}^{r n}=\bar{p}-p_{2}^{r n}<$ 0 , so $p_{1}^{r r}<p_{1}^{r n}, p_{2}^{r r}<p_{2}^{r n}$.

Proof of Proposition 3. From Table 2, (i) if $\bar{w}>w^{r n}, \bar{p}>p_{1}^{r n}$, then $w^{r l}=w^{r n}$ and $p_{1}^{r l}=p_{1}^{r n}, p_{2}^{r l}=p_{2}^{r n}$. (ii) If $\bar{w}<w^{r n}$, $\bar{p}>p_{1}^{r n}$, it is the same as (ii) of the proof of Proposition 1, so $w^{r l}<w^{r n}, p_{1}^{r l}=p_{1}^{r n}, p_{2}^{r l}=p_{2}^{r n}$. (iii) If $\bar{w}>w^{r n}, p_{2}^{r n}<\bar{p}<p_{1}^{r n}$, it is the same as (ii) of the proof of Proposition 2, so $w^{r l}>w^{r n}$ and $p_{1}^{r l}<p_{1}^{r n}, p_{2}^{r l}=p_{2}^{r n}$. (iv) If $\bar{w}<w^{r n}, p_{2}^{r n}<\bar{p}<p_{1}^{r n}$, then $w^{r l}-w^{r n}=\bar{w}-w^{r n}<0$, so $w^{r l}<w^{r n} ; p_{1}^{r l}-p_{1}^{r n}=\bar{p}-p_{1}^{r n}<0$, so $p_{1}^{r l}<p_{1}^{r n}$. From Table 2 , obviously, $p_{2}^{r l}=p_{2}^{r n}$. (v) If $\bar{w}>w^{r n}, \bar{p}<p_{2}^{r n}$, it is the same as (iii) of the proof of Proposition 2, so $w^{r l}>w^{r n}$ and $p_{1}^{r l}<p_{1}^{r n}, p_{2}^{r l}<p_{2}^{r n}$. (vi) If $\bar{w}<w^{r n}, \bar{p}<p_{2}^{r n}$, then $w^{r l}-w^{r n}=\bar{w}-w^{r n}<0, w^{r l}<w^{r n}$; and $p_{1}^{r l}-p_{1}^{r n}=\bar{p}-p_{1}^{r n}<0, p_{2}^{r l}-p_{2}^{r n}=\bar{p}-p_{2}^{r n}<0$, so $p_{1}^{r l}<p_{1}^{r n}$, $p_{2}^{r l}<p_{2}^{r n}$.

Proof of Proposition 4. If $\bar{w}>w^{r n}$, from Table 3, obviously, $\pi_{m}^{r m}=\pi_{m}^{r n}, \quad \pi_{r}^{r m}=\pi_{r}^{r n}, \quad \pi^{r m}=\pi^{r n}$. If $\bar{w}<w^{r n}$, then $\pi_{m}^{r m}-\pi_{m}^{r n}=\left(\bar{w}-w^{r n}\right)\left[\alpha-(\beta-\gamma)\left(p_{1}^{r n}+p_{2}^{r n}\right)\right]<0$, so $\pi_{m}^{r m}<$ $\pi_{m}^{r n} ; \pi_{r}^{r m}-\pi_{r}^{r n}=\left(w^{r n}-\bar{w}\right)\left[\alpha-(\beta-\gamma)\left(p_{1}^{r n}+p_{2}^{r n}\right)\right]>0$, so 
$\pi_{r}^{r m}>\pi_{r}^{r n}$; and $\pi^{r m}-\pi^{r n}=\left(\bar{w}-w^{r n}\right)\left[\alpha-(\beta-\gamma)\left(p_{1}^{r n}+p_{2}^{r n}\right)\right]+$ $\left(w^{r n}-\bar{w}\right)\left[\alpha-(\beta-\gamma)\left(p_{1}^{r n}+p_{2}^{r n}\right)\right]=0$, so $\pi^{r m}=\pi^{r n}$.

Proof of Proposition 5. From formula (6) and the proof of Proposition 4, obviously, if $\bar{w}>w^{r n}$, then $W^{r m}-W^{r n}=0$, so $W^{r m}=W^{r n}$. If $\bar{w}<w^{r n}$, then $W^{r m}-W^{r n}=0$, so $W^{r m}=W^{r n}$.

Proof of Proposition 6. In the RN model, $\left(\mathrm{d} p_{1}^{r n} / \mathrm{d} \theta\right)=$ $(a /(2(\beta+\gamma)))>0$, so $p_{1}^{r n}$ increase in $\theta . \quad\left(\mathrm{d} p_{2}^{r n} / \mathrm{d} \theta\right)=-$ $(a /(2(\beta+\gamma)))<0$, so $p_{2}^{r n}$ decrease in $\theta$, $\quad\left(\left(d \pi_{r}^{r n}\left(p_{1}^{r n}\right.\right.\right.$, $\left.\left.\left.p_{2}^{r n}\right)\right) / d \theta\right)=\left((16(\beta-\gamma) \theta-8(\beta-\gamma)) /\left(16\left(\beta^{2}-\gamma^{2}\right)\right)\right) \alpha^{2}-$ $\left(\left(c_{1}-c_{2}\right) / 2\right), \quad\left(\left(\mathrm{d}^{2} \pi_{r}^{r n}\left(p_{1}^{r n}, p_{2}^{r n}\right)\right) / \mathrm{d}^{2} \theta\right)=\left(\alpha^{2} /(\beta+\gamma)\right)>0$, so $\pi_{r}^{r n}\left(p_{1}^{r n}, p_{2}^{r n}\right)$ is convex in $\theta$. When $\left(\mathrm{d} \pi_{r}^{r n}\left(p_{1}^{r n}, p_{2}^{r n}\right) / \mathrm{d} \theta\right)=0$, $\theta_{0}=(1 / 2)+\left(\left(\left(c_{1}-c_{2}\right)(\beta+\gamma)\right) / 2 \alpha^{2}\right)<(1 / 2)$, so $\theta_{0}<0.7<\theta$ $<1, \pi_{r}^{r n}\left(p_{1}, p_{2}\right)$ increase in $\theta$. In addition, from $w^{r n}=(\alpha /(8(\beta-\gamma)))+\left(\left(6 c-c_{1}-c_{2}\right) / 8\right), \quad \pi_{m}^{r n}\left(w^{r n}\right)=([\alpha-$ $\left.\left.(\beta-\gamma)\left(2 c+c_{1}+c_{2}\right)\right]^{2}\right) /(32(\beta-\gamma))$, they are both independent on $\theta$.

Proof of Proposition 7. In the RL model, if $\bar{w}<w^{r n}, \bar{p}>p_{1}^{r n}$, $\left(\left(\mathrm{d} \pi_{m}^{r l}\left(w^{r l}\right)\right) / \mathrm{d} \phi\right)=\bar{p}\left[\alpha-(\beta-\gamma)\left(p_{1}^{r n}+p_{2}^{r n}\right)\right]>0, \quad\left(\left(\mathrm{~d} \pi_{r}^{r l}\left(p_{1}^{r l}\right.\right.\right.$, $\left.\left.\left.p_{2}^{r l}\right)\right) / \mathrm{d} \phi\right)=-\bar{p}\left(\theta \alpha-\beta p_{1}^{r n}+\gamma p_{2}^{r n}\right)-\bar{p}\left[(1-\theta) \alpha-\beta p_{2}^{r n}+\gamma p_{1}^{r n}\right]<$ 0 . If $\bar{w}<w^{r n}, \quad p_{2}^{r n}<\bar{p}<p_{1}^{r n}, \quad\left(\left(\mathrm{~d} \pi_{m}^{r l}\left(w^{r l}\right)\right) / \mathrm{d} \phi\right)=\bar{p}[\alpha-$ $\left.(\beta-\gamma)\left(\bar{p}+p_{2}^{r n}\right)\right]>0, \quad\left(\left(\mathrm{~d} \pi_{r}^{r l}\left(p_{1}^{r l}, p_{2}^{r l}\right)\right) / \mathrm{d} \phi\right)=-\bar{p}(\theta \alpha-\beta \bar{p}+\gamma$ $\left.p_{2}^{r n}\right)-\bar{p}\left[(1-\theta) \alpha-\beta p_{2}^{r n}+\gamma \bar{p}\right]<0$. If $\bar{w}<w^{r n}, \bar{p}<p_{2}^{r n}$, $\mathrm{d} \pi_{m}^{r l}\left(w^{r l}\right) / \mathrm{d} \phi=\bar{p}[\alpha-2(\beta-\gamma) \bar{p}]>0, \quad \mathrm{~d} \pi_{r}^{r l}\left(p_{1}^{r l}, p_{2}^{r l}\right) / \mathrm{d} \phi=-\bar{p}$ $[\alpha-2(\beta-\gamma) \bar{p}]<0$. So $\pi_{m}^{r l}(w)$ increases in $\phi$ and $\pi_{r}^{r l}\left(p_{1}, p_{2}\right)$ decreases in $\phi$.

\section{Data Availability}

No data were used to support this study.

\section{Conflicts of Interest}

The authors declare no conflicts of interest.

\section{Acknowledgments}

This work was supported by "Young Scholars" program of Xihua University, the program of Research Institute of International Economics and Management Science of Xihua University, the "Chunhui" Plan of Ministry of Education in China (nos. S2011012 and Z2012017), the Key Scientific Research Fund of Xihua University (Grant no. Z1614417), and the Natural Science Foundation of Education Department of Sichuan (no. 17ZB0414). Dr. Shi's researc h was supported by the Natural Sciences and Engineering Research Council of Canada (Grant no. 213090).

\section{References}

[1] United Nations, The Millennium Development Goals Report 2013 [EB/OL], United Nations, New York, NY, USA, 2013, http://www.un.org/millenniumgoals/pdf/report-2013/mdgreport-2013-english.pdf.

[2] World Health Organization, World Health Statistics 2009 [EB/ $O L]$, World Health Organization, Geneva, Switzerland, 2009, http://www.who.int/whosis/whostat/EN_WHS09_Full.
[3] World Health Organization, Health Systems Financing: the Path to Universal Coverage [EB/OL], World Health Organization, Geneva, Switzerland, 2010, http://whqlibdoc.who.int/ whr/2010/9789241564021_eng.pdf.

[4] L. Ye, P. Hernandez, D. Abegunde, and T. Edejer, The World Medicines Situation 2011: Medicine Expenditures [EB/OL], World Health Organization, Geneva, Switzerland, 2011, http://apps.who.int/medicinedocs/documents/s18767en/ s18767en.pdf.

[5] IMS Health, IMS Forecasts Global Pharmaceutical Market Growth of 4-6 Percent in 2010; Predicts 4-7 Percent Expansion through 2013 [EB/OL], IMS Health, Danbury, CT, USA, 2009, https://www.imshealth.com.

[6] K. L. McFadden, S. C. Henagan, and C. R. Gowen III, "The patient safety chain: transformational leadership's effect on patient safety culture, initiatives, and outcomes," Journal of Operations Management, vol. 27, no. 5, pp. 390-404, 2009.

[7] S. A. Narayana, R. Kumar Pati, and P. Vrat, "Managerial research on the pharmaceutical supply chain-a critical review and some insights for future directions," Journal of Purchasing and Supply Management, vol. 20, no. 1, pp. 18-40, 2014.

[8] J. M. de Magalhães and J. P. de Sousa, "Dynamic VRP in pharmaceutical distribution-a case study," Central European Journal of Operations Research, vol. 14, no. 2, pp. 177-192, 2006.

[9] X. Su, "Research on cost control mode of medicine supply chain based on information asymmetry theory," Reform of Economic System, no. 2, pp. 68-73, 2010.

[10] H. P. Zhu, "The endogenous nature of regulation and its consequences: take medicine price control as an example," The Journal of World Economy, vol. 34, no. 7, pp. 64-90, 2011.

[11] J. M. Rong and L. Zhu, "The quality control strategy of dualchannel drug supply chain under government regulation," System Engineering, vol. 37, no. 5, pp. 99-108, 2019.

[12] S. Y. Li, B. Dan, H. X. Li et al., "Power structure for pharmaceutical dual-channel supply China under price cap policy and public welfare," Management Review, vol. 31, no. 9, 2019.

[13] L. M. Wang, Q. K. Song, and Z. J. Zhao, "The optimal pricing of dual-channel supply chain with the third-party product recovery and sales effort," Complexity, vol. 2020, Article ID 4951341, 18 pages, 2020.

[14] Q. Zhang, Z. H. Guo, F. Y. Man et al., "Evaluation and selection of manufacturing suppliers in B2B e-commerce environment," Complexity, vol. 2020, Article ID 8690402, 8 pages, 2020.

[15] Y. Wang and X. Sun, "Dynamic vs. static wholesale pricing strategies in a dual-channel green supply chain," Complexity, vol. 2019, Article ID 8497070, 14 pages, 2019.

[16] A. A. Tsay and N. Agrawal, "Channel conflict and coordination in the e-commerce age," Production and Operations Management, vol. 13, no. 1, pp. 93-110, 2009.

[17] K. Cattani, W. Gilland, H. S. Heese, and J. Swaminathan, "Boiling frogs: pricing strategies for a manufacturer adding a direct channel that competes with offline," Production and Operations Management, vol. 15, no. 1, pp. 40-56, 2006.

[18] W. Huang and J. M. Swaminathan, "Introduction of a second channel: implications for pricing and profits," European Journal of Operational Research, vol. 194, no. 1, pp. 258-279, 2009.

[19] R. Yan and Z. Pei, "The strategic value of cooperative advertising in the dual-channel competition," International Journal of Electronic Commerce, vol. 19, no. 3, pp. 118-143, 2015. 
[20] X. Chen, X. Wang, and X. Jiang, "The impact of power structure on the retail service supply chain with an $\mathrm{O} 2 \mathrm{O}$ mixed channel," Journal of the Operational Research Society, vol. 67, no. 2, pp. 294-301, 2016.

[21] T. Xiao and J. Shi, "Pricing and supply priority in a dualchannel supply chain," European Journal of Operational Research, vol. 254, no. 3, pp. 813-823, 2016.

[22] C. Franco and E. Alfonso-Lizarazo, "A structured review of quantitative models of the pharmaceutical supply chain," Complexity, vol. 2017, Article ID 5297406, 13 pages, 2017.

[23] T. G. Chen, K. Huang, and Z. G. Jiang, "Discrete dynamics in supply chain management," Complexity, vol. 2014, Article ID 913750, 4 pages, 2014.

[24] R. T. Sousa, S. Liu, L. G. Papageorgiou, and N. Shah, "Global supply chain planning for pharmaceuticals," Chemical Engineering Research and Design, vol. 89, no. 11, pp. 2396-2409, 2011.

[25] A. Nagurney and L. S. Nagurney, "Medical nuclear supply chain design: a tractable network model and computational approach," International Journal of Production Economics, vol. 140, no. 2, pp. 865-874, 2012.

[26] A. Nagurney, D. Li, and L. Nagurney, "Pharmaceutical supply chain networks with outsourcing under price and quality competition," International Transactions in Operational Research, vol. 20, no. 6, pp. 859-888, 2013.

[27] N. W. Liang, Research on the Optimization Methods of Logistics System in Pharmaceutical Circulation Enterprise, Central South University, Changsha, China, 2013.

[28] J. Shang, T. P. Yildirim, P. Tadikamalla, V. Mittal, and L. H. Brown, "Distribution network redesign for marketing competitiveness," Journal of Marketing, vol. 73, no. 2, pp. 146-163, 2009.

[29] S. Talluri, K. Cetin, and A. J. Gardner, "Integrating demand and supply variability into safety stock evaluations," International Journal of Physical Distribution \& Logistics Management, vol. 34, no. 1, pp. 62-69, 2004.

[30] K. Danas, A. Roudsari, and P. H. Ketikidis, “The applicability of a multi-attribute classification framework in the healthcare industry," Journal of Manufacturing Technology Management, vol. 17, no. 6, pp. 772-785, 2006.

[31] Y. Boulaksil and J. C. Fransoo, "Implications of outsourcing on operations planning: findings from the pharmaceutical industry," International Journal of Operations \& Production Management, vol. 30, no. 10, pp. 1059-1079, 2010.

[32] Z. Shen, M. Dessouky, and F. Ordonez, "Perishable inventory management system with a minimum volume constraint," Journal of the Operational Research Society, vol. 62, no. 12, pp. 2063-2082, 2011.

[33] A. Pazirandeh, "Sourcing in global health supply chains for developing countries: literature review and a decision making framework," International Journal of Physical Distribution \& Logistics Management, vol. 41, no. 4, pp. 364-384, 2011.

[34] H. Zhao, C. Xiong, S. Gavirneni, and A. Fein, "Fee-for-service contracts in pharmaceutical distribution supply chains: design, analysis, and management," Manufacturing \& Service Operations Management, vol. 14, no. 4, pp. 685-699, 2012.

[35] X. Ying and L. Breen, "Greening community pharmaceutical supply chain in UK: a cross boundary approach," Supply Chain Management: An International Journal, vol. 17, no. 1, pp. 40-53, 2012.

[36] L. Niziolek, T. C. Chiam, and Y. Yih, "A simulation-based study of distribution strategies for pharmaceutical supply chains," IIE Transactions on Healthcare Systems Engineering, vol. 2, no. 3, pp. 181-189, 2012.
[37] S. K. Mukhopadhyay, D.-Q. Yao, and X. Yue, "Information sharing of value-adding retailer in a mixed channel hi-tech supply chain," Journal of Business Research, vol. 61, no. 9, pp. 950-958, 2008.

[38] W. Shang, A. Y. Ha, and S. Tong, "Information sharing in a supply chain with a common retailer," Management Science, vol. 62, no. 1, pp. 245-263, 2015.

[39] X. Chen, X. Wang, and K. Gong, "The effect of bidimensional power structure on supply chain decisions and performance," IEEE Transactions on Systems, Man, and Cybernetics: Systems, vol. 50, no. 3, pp. 1095-1110, 2020.

[40] S. Cowan, "Welfare consequences of tight price-cap regulation," Bulletin of Economic Research, vol. 50, no. 2, pp. 105-116, 1998.

[41] Y. Jin, S. Wang, and Q. Hu, "Contract type and decision right of sales promotion in supply chain management with a capital constrained retailer," European Journal of Operational Research, vol. 240, no. 2, pp. 415-424, 2015.

[42] J. Li, L. Yi, V. Shi, and X. Chen, "Supplier encroachment strategy in the presence of retail strategic inventory: centralization or decentralization?" Omega, Article ID 102213, 2020.

[43] S. Li, Y. He, and L. Chen, "Dynamic strategies for supply disruptions in production-inventory systems," International Journal of Production Economics, vol. 194, pp. 88-101, 2017.

[44] J. Bian, Y. Liao, Y. Y. Wang, and F. Tao, "Analysis of firm CSR strategies," European Journal of Operational Research, 2020.

[45] X.-X. Zheng, Z. Liu, K. W. Li, J. Huang, and J. Chen, "Cooperative game approaches to coordinating a three-echelon closed-loop supply chain with fairness concerns," International Journal of Production Economics, vol. 212, pp. 92-110, 2019. 